\title{
Two Ways to the Top: Evidence That Dominance and Prestige Are Distinct Yet Viable Avenues to Social Rank and Influence
}

\author{
Joey T. Cheng and Jessica L. Tracy \\ University of British Columbia
}

\author{
Tom Foulsham \\ University of Essex
}

\author{
Joseph Henrich \\ University of British Columbia and Canadian Institute for \\ Advanced Research, Toronto, Ontario, Canada
}

\begin{abstract}
The pursuit of social rank is a recurrent and pervasive challenge faced by individuals in all human societies. Yet, the precise means through which individuals compete for social standing remains unclear. In 2 studies, we investigated the impact of 2 fundamental strategies-Dominance (the use of force and intimidation to induce fear) and Prestige (the sharing of expertise or know-how to gain respect) - on the attainment of social rank, which we conceptualized as the acquisition of (a) perceived influence over others (Study 1), (b) actual influence over others' behaviors (Study 1), and (c) others' visual attention (Study 2). Study 1 examined the process of hierarchy formation among a group of previously unacquainted individuals, who provided round-robin judgments of each other after completing a group task. Results indicated that the adoption of either a Dominance or Prestige strategy promoted perceptions of greater influence, by both group members and outside observers, and higher levels of actual influence, based on a behavioral measure. These effects were not driven by popularity; in fact, those who adopted a Prestige strategy were viewed as likable, whereas those who adopted a Dominance strategy were not well liked. In Study 2, participants viewed brief video clips of group interactions from Study 1 while their gaze was monitored with an eye tracker. Dominant and Prestigious targets each received greater visual attention than targets low on either dimension. Together, these findings demonstrate that Dominance and Prestige are distinct yet viable strategies for ascending the social hierarchy, consistent with evolutionary theory.
\end{abstract}

Keywords: Dominance, Prestige, social status, social influence, social hierarchy

From 1945 to 1980, Henry Ford II-grandson of Henry Ford, founder of Ford Motor Company-built Ford into the second largest industrial corporation worldwide, amidst a turbulent post-

This article was published Online First November 19, 2012.

Joey T. Cheng and Jessica L. Tracy, Department of Psychology, University of British Columbia, Vancouver, British Columbia, Canada; Tom Foulsham, Department of Psychology, University of Essex, Colchester, England; Alan Kingstone, Department of Psychology, University of British Columbia; Joseph Henrich, Department of Psychology and Department of Economics, University of British Columbia, and Canadian Institute for Advanced Research, Toronto, Ontario, Canada.

We would like to thank Social Sciences Research Council of Canada (File Nos. 767-2009-2108 and 410-2009-2458), Michael Smith Foundation for Health Research (File No. CI-SCH-01862(07-1)), Canadian Institute for Health Research, and Canadian Institute for Advanced Research for supporting this research. We are grateful to Robb Willer, Marc Fournier, Alec Beall, Jason Martens, Jack Eurich, Cameron Anderson, Jeremy Biesanz, Joan Silk, and David Kenny for their valuable comments and advice on this work, and to Sophia Ongley, Kazushi Nishino, and research assistants from the University of British Columbia Emotion and Self Lab for their assistance with data collection.

Correspondence concerning this article should be addressed to Joey T. Cheng, Department of Psychology, University of British Columbia, 2136 West Mall, Vancouver BC V6T 1Z4, Canada. E-mail: joeycheng@ psych.ubc.ca
World War II economy. Ford II attained his success, in part, by developing a reputation for erratic outbursts of temper and unleashing humiliation and punishment at will upon his employees, who described him as a terrorizing dictator, bigot, and hypocrite. When challenged or questioned by subordinates, Ford II would famously remind those who dared contradict him, "My name is on the building." Yet, despite being widely regarded as one of the most intimidating and autocratic CEOs to ever grace the company, Ford II was an enormously successful leader, and has been credited with reviving the Ford business legend during a period of turmoil and crisis (Iacocca, 1984).

A contrasting example of effective leadership can be seen in Warren Buffett, chairman and chief executive officer of Berkshire Hathaway, who was ranked the world's wealthiest person in 2008, and third wealthiest in 2011. Widely regarded as one of the most skilled and successful investors, and referred to as "the sage and oracle of Omaha," Buffett is extraordinarily respected by business leaders, who regularly travel to his Berkshire Hathaway headquarters in Nebraska to seek his wisdom. Buffett's Prestige extends well beyond the business and investment realm; in 2011, he was ranked one of the top five most admired and respected men in the world (Jones, 2011). Under his leadership, Berkshire Hathaway has consistently emerged as one of the most highly regarded U.S. companies, based on public polls (Malone, 2010). Despite this high level of success, Buffet exemplifies a markedly different 
leadership style from that of Ford II. Buffett has developed a reputation for subtly steering rather than controlling every decision-making process, and is known to demonstrate trust and respect toward his executives. The fact that both these men reached what can only be considered the highest pinnacle of social rank possible in any industry, yet did so using highly divergent approaches to leadership, raises the question, Are there multiple ways of ascending the social hierarchy in human societies?

\section{The Nature of Social Hierarchy}

Hierarchical differences, defined as the "rank order of individuals or groups on a valued social dimension" (Magee \& Galinsky, 2008, p. 354), are a universal feature of social groups (Brown, 1991; Mazur, 1985; Murdock, 1949). In all human societies, hierarchical differences among individuals influence patterns of conflict, resource allocation, and mating, and often facilitate coordination on group tasks (Báles, 1950; Berger, Rosenholtz, \& Zelditch, 1980; de Kwaadsteniet \& van Dijk, 2010; Ellis, 1995; Fried, 1967; Ronay, Greenaway, Anicich, \& Galinsky, 2012). Even the most egalitarian of foragers reveal such rank differences, despite the frequent presence of social norms that partially suppress them (Boehm, 1993; R. B. Lee, 1979; H. Lewis, 1974; see Henrich \& Gil-White 2001). High-ranking individuals tend to have disproportionate influence within a group, such that social rank can be defined as the degree of influence one possesses over resource allocation, conflicts, and group decisions (Berger et al., 1980). In contrast, low-ranking individuals must give up these benefits, deferring to higher ranking group members. As a result, higher social rank tends to promote greater fitness than low rank, and a large body of evidence attests to a strong relation between social rank and fitness or well-being, across species (e.g., Barkow, 1975; Betzig, 1986; Cowlishaw \& Dunbar, 1991; J. Hill, 1984b; K. Hill \& Hurtado, 1989; von Rueden, Gurven, \& Kaplan, 2011; Sapolsky, 2005).

Despite its ubiquity, the process of hierarchical differentiation in humans is not well understood. In the face of a growing body of research, it remains unclear precisely how individuals attain and successfully compete for social rank and influence. At least two major accounts of rank attainment currently prevail in the literature, but they are directly at odds with each other, resulting in an ongoing debate within the field (Anderson, Srivastava, Beer, Spataro, \& Chatman, 2006). On one hand, a number of theorists have argued that rank acquisition relies on the attainment and demonstration of superior skills and abilities, as well as altruistic tendencies, arguing that "individuals do not attain status by bullying and intimidating . . . but by behaving in ways that suggest high levels of competence, generosity, and commitment" (Anderson \& Kilduff, 2009a, p. 295; see also Berger, Cohen, \& Zelditch, 1972; Hollander \& Julian, 1969). In contrast, others argue that individuals can effectively ascend a group's hierarchy and attain influence by using manipulative and coercive tactics such as intimidation and "aggression ... [which] function to increase one's status or power" (Buss \& Duntley, 2006, p. 267), and that the human hierarchical system is at least partially "based ... on overt threats and physical attack" (Mazur, 1973, p. 526; see also Chagnon, 1983; Griskevicius et al., 2009; K. Hill \& Hurtado, 1996). These incompatible perspectives beg some resolution. Here, we argue that in contrast to both these opposing perspectives, neither intim- idation nor competence can be considered an exclusive means of rank acquisition in humans. Instead, both of these processes may operate concurrently within social groups, such that individuals can pursue either path to successfully ascend the hierarchy (Cheng, Tracy, \& Henrich, 2010; Henrich \& Gil-White, 2001).

We tested this novel account of rank attainment by examining whether individuals who adopt these distinct behavioral pathways emerge as high-ranking members of their social group. Specifically, in accordance with prior research, we operationalized social rank in terms of social influence (i.e., the ability to modify others' behaviors, thoughts, and feelings; Báles, Strodtbeck, Mills, \& Roseborough, 1951; Berger et al., 1972; Cartwright, 1959; French \& Raven, 1959; Henrich \& Gil-White, 2001; Magee \& Galinsky, 2008; Mazur, 1973; Moore, 1968) and attention received from others (Anderson \& Shirako, 2008; Chance, 1967; Fiske, 1993; Hold, 1976; see Anderson, John, Keltner, \& Kring, 2001), and predicted that each of two distinct rank-ascending strategiesDominance and Prestige-would be associated with rank attainment.

\section{Perspectives on Hierarchical Differentiation}

\section{The Competence-Based Account of Hierarchy Differentiation}

Most accounts of social hierarchies take a competence-centered perspective (e.g., Berger et al., 1972; Blau, 1964; Hollander \& Julian, 1969; Thibaut \& Kelley, 1959), in which an individual's rank is considered to be a function of the group's collective consensus on the individual's social worth. In other words, influence is conferred by the group upon individuals perceived to possess superior expertise and competence in valued domains (Berger et al., 1972). This system of rank allocation is thought to serve a number of functions, such as increasing perceptions that the hierarchy is legitimate and fair-which minimizes conflictand allowing the group to maximize contributions from its most competent members to best achieve shared goals.

The competence-based perspective on rank attainment has garnered considerable empirical support. For example, numerous studies have demonstrated that the characteristics valued and prioritized in leaders-intelligence, competence, group commitment, and prosociality - consistently predict high rank, defined in terms of perceived influence and leadership, as well as more objective influence over group decisions (Báles, Strodtbeck, Mills, \& Roseborough, 1951; Coie, Dodge, \& Coppotelli, 1982; Driskell, Olmstead, \& Salas, 1993; Lord, de Vader, \& Alliger, 1986; Strodtbeck, 1951; Willer, 2009; for a review, see Anderson \& Kilduff, 2009a). More specifically, studies have found that influence is granted to individuals who make high-quality comments (Gintner \& Lindskold, 1975; Sorrentino \& Boutillier, 1975), are perceived as experts (Bottger, 1984; Littlepage, Schmidt, Whisler, \& Frost, 1995; Ridgeway, 1987), and make large contributions to a public fund (Willer, 2009). In fact, Anderson and Kilduff (2009b) found that in task-focused groups, perceptions of competence were the most important contributor to social influence.

Importantly, a core principle of the competence-based account is that influence cannot be attained through coercive tactics such as bullying or intimidation, and instead derives only from one's 
apparent value to the group (Anderson \& Kilduff, 2009a, 2009b; Ridgeway, 1987; Ridgeway \& Diekema, 1989). One of the strongest proponents of this account is Barkow (1975), who argues that hierarchical relationships based purely on threat of force are untenable in human societies. This assumption is in direct opposition to the other major extant account of rank attainment within the social science literature, the conflict-based account.

\section{The Conflict-Based Account of Hierarchy Differentiation}

According to the conflict-based account, Dominance contests (i.e., ritualized agonistic challenges, threats, or attacks resulting in the submission of one party to another) and coercion function as the most fundamental systems of rank allocation in human societies (Buss \& Duntley, 2006; Chagnon, 1983; Griskevicius et al., 2009; K. Hill \& Hurtado, 1996; Kyl-Heku \& Buss, 1996; M. T. Lee \& Ofshe, 1981; Mazur, 1973). In this view, rank (i.e., social influence) is allocated to individuals who show a Dominant, authoritative demeanor, and not, as the competence-based perspective suggests, on the basis of rational calculation about others' abilities or expertise.

Consistent with this account, a number of studies indicate that rank is often associated with intimidation and threat; perceived influence, leadership, and actual resource control have all been found to positively correlate with coercive behavior, toughness, and various forms of aggression (Cashdan, 1998; Hawley, 2002). Results of a meta-analysis found that the personality trait of Dominance-defined as a propensity toward forceful, assertive, and aggressive behaviors-explains a substantial proportion of variance in perceptions of leadership, even more so than intelligence (Lord et al., 1986). Furthermore, when asked to nominate strategies typically used for negotiating hierarchies, individuals report aggression, coercion, derogation, social exclusion, and manipulation as frequently used tactics, along with tactics consistent with the competence-based account, such as displaying knowledge, working hard, and helping others (Buss, Gomes, Higgins, \& Lauterbach, 1987; Kyl-Heku \& Buss, 1996). These findings suggest that lay individuals conceptually associate each of these two behavioral patterns with the acquisition of social rank. More broadly, there is evidence that the motivation to seek or maintain one's rank promotes aggressive behaviors (though this research did not examine the effectiveness of these behaviors). Approximately $48 \%$ of men and $45 \%$ of women identify status and reputation concerns as the primary reason for their last act of aggression, and the experimental induction of status motives increases aggressive tendencies in both men and women (Griskevicius et al., 2009). Although it remains unclear whether aggression and intimidation are effective routes to attaining influence, these findings are suggestive, and cannot be easily reconciled with the competence-based account.

\section{The Dominance-Prestige Account of Hierarchy Differentiation}

A third account of social rank acquisition, the DominancePrestige model, draws on evolutionary theory to take into account our species' dual heritage as primates who tend to use coercive Dominance, and as cultural beings who rely immensely on cultural learning and shared knowledge (Henrich \& Gil-White, 2001). By considering the selection pressures that likely favored the emergence of hierarchical groups, Henrich and Gil-White (2001) proposed that there are two distinct paths to social rank attainment in human societies: Dominance and Prestige. Dominance refers to the induction of fear, through intimidation and coercion, to attain social rank, a process similar to that described by the conflictbased account. Prestige, in contrast, refers to social rank that is granted to individuals who are recognized and respected for their skills, success, or knowledge (which can be acquired via cultural learning), a process similar to that described by the competencebased account. The major difference between the DominancePrestige Account and these prior accounts is that it explicitly argues, on the basis of evolutionary logic, that both strategies persist in modern humans, lead to patterns of behavior and tactics that provide effective means to social influence, and can be effective even within the same social groups.

Dominance is exemplified by relationships based on coercion, such as that between a boss and employee, or bully and victim. Dominant individuals create fear in subordinates by unpredictably and erratically taking or threatening (implicitly or explicitly) to withhold resources; in turn, subordinates submit by complying with Dominants' demands, in order to safeguard other more valuable resources (e.g., their physical welfare, children, or livelihoods). As a result, Dominants can attain a great deal of social influence. Prestige, in contrast, is granted to individuals who are considered worthy of emulation, usually for their skills or knowledge. As a result, the opinions, wishes, and decisions of Prestigious individuals tend to be heeded, thus conferring them with high rank. The influence of Prestigious individuals is unique in that subordinates shift their views and opinions closer to those of the Prestigious (an example of emulation) and heed their wishes out of deference even when they do not agree with them (an example of seeking favor, in order to be granted greater access to Prestigious leaders to facilitate their own copying or learning).

According to the model, Dominance initially arose in evolutionary history as a result of agonistic contests for material resources and mates that were common among nonhuman species, but continues to exist in contemporary human societies, largely in the form of psychological intimidation, coercion, and wielded control over costs and benefits (e.g., access to resources, mates, and well-being). In both humans and nonhumans, Dominance hierarchies are thought to emerge to help maintain patterns of submission directed from subordinates to Dominants, thereby minimizing agonistic battles and incurred costs.

In contrast, Prestige is likely unique to humans, because it is thought to have emerged from selection pressures to preferentially attend to and acquire cultural knowledge from highly skilled or successful others, a capacity considered to be less developed in other animals (Boyd \& Richerson, 1985; Laland \& Galef, 2009). In this view, social learning (i.e., copying others) evolved in humans as a low-cost fitness-maximizing, information-gathering mechanism (Boyd \& Richerson, 1985). Once it became adaptive to copy skilled others, a preference for social models with better than average information would have emerged. This would promote competition for access to the highest quality models, and deference toward these models in exchange for copying and learning opportunities. Consequently, selection likely favored Prestige differentiation, with individuals possessing high-quality information or 
skills elevated to the top of the hierarchy. Meanwhile, other individuals may reach the highest ranks of their group's hierarchy by wielding threat of force, regardless of the quality of their knowledge or skills. Thus, Dominance and Prestige can be thought of as coexisting avenues to attaining rank and influence within social groups, despite being underpinned by distinct motivations and behavioral patterns, and resulting in distinct patterns of imitation and deference from subordinates.

Importantly, both Dominance and Prestige are best conceptualized as cognitive and behavioral strategies (i.e., suites of subjective feelings, cognitions, motivations, and behavioral patterns that together produce certain outcomes) deployed in certain situations, and can be used (with more or less success) by any individual within a group. They are not types of individuals, or even, necessarily, traits within individuals. Instead, we assume that all situated dyadic relationships contain differential degrees of both Dominance and Prestige, such that each person is simultaneously Dominant and Prestigious to some extent, to some other individual. Thus, it is possible that a high degree of Dominance and a high degree of Prestige may be found within the same individual, and may depend on who is doing the judging. For example, by controlling students' access to rewards and punishments, school teachers may exert Dominance in their relationships with some students, but simultaneously enjoy Prestige with others, if they are respected and deferred to for their competence and wisdom. Indeed, previous studies have shown that based on both self- and peer ratings, Dominance and Prestige are largely independent (mean $r=-.03$; Cheng et al., 2010)

\section{Differentiating Dominance and Prestige From Other Conceptualizations of Social Rank}

Although this distinction between Dominance and Prestige is consistent with a long-standing theoretical differentiation between "power" and "status" in social psychology and sociology (see Blau, 1964; Fiske, 2010; Kemper, 2006; Magee \& Galinsky, 2008; Weber, 1964), it is important to note several critical differences between the two frameworks (see also Table 1).

First, our conceptualization of Dominance differs from power in that Dominance is relevant to contexts with and without institu-

Table 1

Definitions of Hierarchy-Related Concepts in Psychology and Related Fields

\begin{tabular}{llll}
\hline Concept & Social psychology/sociology & Personality psychology & Sociobiology/biology \\
\hline Dominance & Not a core concept & $\begin{array}{l}\text { The tendency to behave in } \\
\text { assertive, forceful, and } \\
\text { self-assured ways; the } \\
\text { desire for control and }\end{array}$ & $\begin{array}{l}\text { An individual's relatively stable } \\
\text { position in a social hierarchy } \\
\text { resulting from his or her } \\
\text { relative success in previous } \\
\text { agfluence }\end{array}$ \\
& & $\begin{array}{l}\text { agonistic or competitive } \\
\text { encounters with conspecifics }\end{array}$
\end{tabular}

Prestige

Generally not a core concept; if used, tends to be interchanged with status

Power

The relative degree of asymmetric control or influence an individual possesses over resources, often despite resistance ${ }^{\mathrm{g}}$

Status
The relative degree to which an individual is respected or admired by others ${ }^{\mathrm{h}}$
Not a core concept

The relative degree of deference, respect, and attention an individual receives from others $^{\mathrm{e}}$

$\begin{array}{ll}\begin{array}{l}\text { Used interchangeably with } \\ \text { Dominance and status }\end{array} & \text { Not a core concept } \\ \begin{array}{c}\text { Used interchangeably with } \\ \text { Dominance and power }\end{array} & \begin{array}{l}\text { Used interchangeably with } \\ \text { Dominance, but also } \\ \text { infrequently with Prestige }\end{array}\end{array}$

Evolutionary psychology

The relative degree of deference, respect, and attention an individual receives from others as a consequence of his or her perceived ability to use coercion, intimidation, and imposition (control costs and benefits) ${ }^{\mathrm{d}}$

The relative degree of deference, respect, and attention an individual receives from others as consequence of one's perceived attractiveness as a cultural model or coalition partner ${ }^{\mathrm{f}}$

Not a core concept

\footnotetext{
The relative degree to which an individual receives (relatively) unchallenged deference, influence, social attention, and access to valued resources ${ }^{\mathrm{i}}$ (Prestige and Dominance are types of status)
}

Note. The core concepts presented here are those that focus on differences among individuals rather than group-level differences (e.g., social Dominance orientation; Sidanius \& Pratto, 1999). The definitions provided aim to capture the broad and modal use of each label in the respective literature, but of course there exists some degree of terminological variation within each literature.

${ }^{a}$ Social psychology and sociology are combined here because these two fields show substantial agreement in their use of these terminologies. ${ }^{\mathrm{b}}$ Anderson \& Kilduff (2009b); Buss \& Craik (1980); Carson (1969); Gough (1987); Jackson (1999); Leary (1957); Moskowitz (1988); Murray (1938); Wiggins (1979). $\quad{ }^{\mathrm{c}}$ Bernstein (1970, 1981); Fournier (2009); Hinde (1974); Jolly (1972); Maynard Smith (1974); Maynard Smith \& Price (1973); Mazur (1985); Savin-Williams (1976); Strayer et al. (1975); Strayer \& Strayer (1976); E. O. Wilson (1975). ${ }^{\text {d }}$ Buss (2008); Henrich \& Gil-White (2001); Johnson et al. (2007); von Rueden et al. (2008, 2011). ${ }^{\mathrm{e}}$ Barkow (1975, 1989); Casimir \& Rao (1995); Gilbert et al. (1995); J. Hill (1984a, 1984b). ${ }^{\mathrm{f}}$ Buss (2008); Henrich \& Gil-White (2001); Plourde (2008); von Rueden et al. (2008, 2011); Wood (2006). ${ }^{\mathrm{g}}$ Blader \& Chen (2012); Boldry \& Gaertner (2006); Dépret \& Fiske (1993); Emerson (1962); French \& Raven (1959); Galinsky et al. (2003); Keltner et al. (2003); Kemper (1990, 2006); Lewin (1951); Magee \& Galinsky (2008). ${ }^{\mathrm{h}}$ Anderson \& Kilduff (2009a, 2009b); Blau (1964); Fiske (2010); Goldhamer \& Shils (1939); Kemper (1990, 2006); Magee \& Galinsky (2008); Ridgeway \& Walker (1995); Zelditch (1968). ${ }^{i}$ Henrich \& Gil-White (2001); von Rueden et al. (2008). 
tionalized positions, whereas power inequalities are primarily found in groups with institutionalized hierarchies and formally appointed leaders or power holders. Power has traditionally been defined as "asymmetric control over valued resources" (Magee \& Galinsky, 2008, p. 361; see also Blader \& Chen, 2012; Boldry \& Gaertner, 2006; Dépret \& Fiske, 1993; Emerson, 1962; French \& Raven, 1959; Galinsky, Gruenfeld, \& Magee, 2003; Keltner, Gruenfeld, \& Anderson, 2003; Lewin, 1951), consistent with an emphasis on externally endowed positions that allow one to determine rewards and punishment for others. Thus, it is not clear how power can lead to hierarchical differentiation in groups without formalized ranks (e.g., friendship groups, work groups without a predetermined leader). In these contexts, all group members share a similar degree of control over critical resources, and no single individual is typically privileged with greater power than any other. Thus, power is not particularly applicable to spontaneously forming hierarchies among groups of previously unacquainted individuals, such as those examined in the current research. In addition, although powerful individuals likely possess Dominance, given that they have asymmetric control over rewards and punishments (and thus can elicit fear), Dominant individuals do not necessarily have power, in the form of institutional control over others' reward and punishment outcomes. Furthermore, in contrast to Dominance, power cannot be considered a rankobtaining strategy that individuals can use to ascend a social hierarchy. One either has control over resources (i.e., power) or does not, making power an outcome, but not a strategy or process that produces hierarchical differentiation (see R. J. Lewis, 2002).

Second, although Prestige is consistent with the conceptual label of "social status" in social psychology and sociology—defined as "the extent to which an individual or group is respected or admired by others" (Magee \& Galinsky, 2008, p. 359; see also Anderson \& Kilduff, 2009a, 2009b; Blau, 1964; Fiske, 2010; Goldhamer \& Shils, 1939; Ridgeway \& Walker, 1995; Zelditch, 1968)—the term Prestige is better suited for our theoretical framework because status has notably different definitions in other disciplines (including several that we explicitly draw on), leading to the potential for considerable confusion (see Table 1). In particular, in personality psychology, status refers to Dominance, influence, agency, and control (Carson, 1969; Leary, 1957; Wiggins, 1979), and not to respect or admiration. In biology and zoology, status refers to relative physical prowess and ritualized outcomes in agonistic encounters (Bernstein, 1981; Rabb, Woolpy, \& Ginsburg, 1967; Rowell, 1974; Sapolsky, 2005; Schenkel, 1967; Trivers, 1985), making it similar to Dominance. In sociobiology (the field from which evolutionary psychology originated), status has been used similarly, to refer to social Dominance and physical domination (Barkow, 1975; Ellis, 1995; J. Hill, 1984a, 1984b). In contrast, Prestige is defined in a highly consistent manner across all these disciplines; in all cases it is conceptualized as conferred respect, honor, esteem, and social regard (Anderson et al., 2001; Anderson \& Kilduff, 2009a, 2009b; Barkow, 1975; Buss, 2008; EiblEibesfeldt, 1989; Goldhamer \& Shils, 1939; Henrich \& Gil-White, 2001; Ridgeway \& Walker, 1995).

Third, despite their theoretical differentiation, power and status have repeatedly been found to be strongly positively correlated, in both naturalistic and laboratory-based groups (Barth \& Noel, 1972; Carli \& Eagly, 1999; Guinote, Judd, \& Brauer, 2002; Hewstone, Rubin, \& Willis, 2002; Sidanius \& Pratto, 1999). These correla- tions likely result from the fact that influence is a consequence of both power and status, but is conceptually distinct (Fiske \& Berdahl, 2007; Magee \& Galinsky, 2008). For example, one of the most frequently employed experimental manipulations of power involves real or imagined assignment to manager versus subordinate roles. One potential problem with this manipulation is that some participants assigned the "manager" role may lead and exert influence via their ability to control rewards and punishments (i.e., power), whereas others may do so by demonstrating competence and expertise (i.e., status, or in our terminology, Prestige), and still others may choose to pursue both strategies in different relationships. Because distinctions are typically not made between these various strategies and behaviors, they become conflated, resulting in a positive correlation between power as manipulated in this manner and status as assessed via respect and admiration. In contrast, Dominance and Prestige are theoretically and empirically independent constructs, regardless of whether they are assessed with self-perceptions in the form of generalized Dominance and Prestige across a range of relationships $(r=.03, p=.65)$, or in a specific, naturalistic context $(r=.07, p=.54)$, or via peer perceptions ( $r=.12, p=.23$; see Cheng et al., 2010).

Thus, by making a clear theoretical distinction between the two strategies used to attain social rank, we can assess Dominance and Prestige as separate constructs, and avoid contamination of either with other related but still distinct constructs such as social influence. At a broader level, the use of the concepts and terminology developed in the Dominance-Prestige model allows us to maintain consistency with that model's evolutionarily derived theory, as well as the biological literature on primates; in contrast, labels such as "power" and "status" may be consistent with folk terminology but less theoretically grounded. For example, it is not clear how the concepts of power or status could be applied to nonhuman primates (e.g., baboons and chimpanzees), whereas the Dominance concept places humans firmly within the natural world. Indeed, biologists and anthropologists have developed an immense body of research on Dominance in primates and other animals (e.g., Bernstein, 1976; de Waal, 1986; Eibl-Eibesfeldt, 1970; Lorenz, 1964; Mazur, 1985; Sapolsky, 2005; Schjelderup-Ebbe, 1935), so by adopting this framework we can draw on insights from these literatures to enrich our understanding of human rank dynamics. There are a number of reasons to suspect that human Dominance shares phylogenetic continuity with Dominance patterns observed in other primates (Eibl-Eibesfeldt, 1961; Henrich \& Gil-White 2001; Mazur, 1985; Tracy, Shariff, \& Cheng, 2010).

Several studies of human rank dynamics have drawn on the Dominance-Prestige Account to measure these two strategies, typically as trait-like dispositions that vary among individuals, and supportive findings have emerged. First, individuals who tend to use a Dominance strategy across numerous relationships (from here on referred to as individuals high in Dominance, or Dominant individuals) tend to be aggressive, narcissistic, and Machiavellian, whereas those who tend to use a Prestige strategy across relationships (from here on referred to as individuals high in Prestige, or Prestigious individuals) tend to be socially accepted, agreeable, and conscientious and have high self-esteem (Buttermore, 2006; Cheng et al., 2010; Johnson, Burk, \& Kirkpatrick, 2007). These findings are based on assessments of Dominance and Prestige with both self- and peer ratings. Second, Prestigious individuals tend to demonstrate locally valued competencies and skills, such as aca- 
demic achievement, altruistic behaviors, and athletic, social, intellectual, and advice-giving abilities (in the context of collegiate varsity teams; Cheng et al., 2010); and hunting ability, skill in food production, generosity, number of allies, and nutritional status (in the context of a small-scale Amazonian society; Reyes-García et al., 2008, 2009; von Rueden, Gurven, \& Kaplan, 2008). Third, there is evidence for distinct neuroendocrine profiles; individuals high in Prestige tend to have lower basal testosterone levels, a hormone linked to aggressive behavior, relative to individuals low in Prestige (Johnson et al., 2007). These findings have led researchers (and textbooks) in evolutionary psychology to adopt the terminology and concepts of the Dominance and Prestige model (e.g., Buss, 2008).

In sum, the Dominance-Prestige Account provides a way of reconciling the two currently reigning, and opposing, approaches to understanding human hierarchical differentiation and the attainment of social rank. As a result, this model has two key advantages over these prior perspectives. First, although prior models that emphasize the narrow traits and attributes (e.g., aggressiveness, intelligence) predictive of high rank serve a descriptive function (i.e., providing information about the kinds of individuals who tend to attain rank, on average, across many contexts), they do not provide a causal or explanatory account. That is, such models do not address questions of why these behaviors effectively promote influence. The Dominance-Prestige Account, in contrast, uses evolutionary logic to generate a priori hypotheses about the processes underlying rank attainment in humans, such that when these hypotheses are supported, findings explain (rather than simply describe) why a vast number of narrower attributes and characteristics give rise to influence.

Second, the Dominance-Prestige approach emphasizes broad social processes, involving fear and respect, rather than the narrower stable attributes and traits thought to underlie influence in other accounts. Although these narrower characteristics may elicit feelings of fear or respect in others (and by implication, be part of the broader Dominance or Prestige constructs), these links are highly context specific. For example, an intelligent college professor probably holds little influence over a recreational soccer team, compared with the team's star soccer player. In other words, stable traits and characteristics produce admiration and fear in some contexts but not others, so have limited utility in explaining cross-situational patterns of rank allocation. Thus, in the present research, we assessed individuals' relationships with group members broadly, using items such as "I respect and admire him/her," "I seek his/her advice on a variety of matters," and "I'm afraid of him/her" (see Cheng et al., 2010). These items tap directly into the critical interpersonal perceptions central to Dominance and Prestige processes, in contrast to the narrow, static attributes typically examined in previous studies (e.g., toughness, intelligence).

Importantly, despite the potential benefits of the DominancePrestige Account for explaining patterns of rank allocation in human groups and resolving prior controversies, no studies to date have empirically validated the theorized effects of Dominance and Prestige on the attainment of social rank. Thus, in the current research, we sought to conduct the first test of whether Dominance and Prestige are alternative avenues to attaining social rank, such that individuals within the same social group can be reliably identified as demonstrating behaviors and motivations associated with each, and can effectively attain social rank and influence using either strategy.

\section{Preliminary Evidence on the Association Between Dominance, Prestige, and Social Rank}

Although no empirical efforts to date have directly examined whether Dominance and Prestige are concurrently associated with increased social rank and influence, several studies have documented positive relations between influence and narrower attributes and behaviors that are theoretically related to Dominance or Prestige within the same social groups. For example, Hawley (2002, 2003) found that among children aged 3-6, narrow coercive behaviors such as taking away a toy, insulting, or physically aggressing against another child were as likely to promote control over a desired toy as were narrow prosocial behaviors such as making suggestions and offering help. Other developmental studies have found that children who are more frequently imitated, obeyed, and preferred as interaction partners, as well as children who frequently win agonistic encounters, tend to receive the most looks or glances from their peers (Abramovitch, 1976; La Freniere \& Charlesworth, 1983; Hold, 1976; Vaughn \& Waters, 1981). Similarly, teacher-rated aggressiveness, observed Dominant acts, peer liking, and the degree to which a child is imitated have all been found to predict the number of glances received from other children (Abramovitch \& Grusec, 1978; La Freniere \& Charlesworth, 1983; but see Vaughn \& Waters, 1981). In this literature, others' glances or visual attention is typically operationalized as an indicator of social rank.

Though none of these studies assessed Dominance or Prestige as the broad constructs that they are-constituted of a range of distinct behaviors and tendencies - these findings provide preliminary support for the suggestion that either strategy may effectively promote rank and influence. However, several researchers have argued that hierarchical dynamics work differently in children's social groups, in that children tolerate the use of force and coercion to obtain social rank, but adults do not (Barkow, 1975; SavinWilliams, 1980; but see Strayer \& Trudel, 1984). In line with this view, Savin-Williams (1979) found that among children and early adolescents (age 9-13), narrow characteristics and behaviors theoretically associated with Dominance (e.g., pubertal maturation, physical fitness, physical and verbal threats, taking or removing objects) were the strongest predictors of influence, but among middle to late adolescents (age 14-17), these same variables were unrelated to influence (Savin-Williams, 1980). Further supporting this developmental account, Hawley (2002) found that coercive 3to 6-year-old children were rated as more likable by their peers, an effect directly opposed to findings in adults, who typically dislike and reject coercive, arrogant, and aggressive individuals (Cheng et al., 2010). It thus remains to be seen whether Dominance and Prestige are viable routes to attaining influence in adult social groups. According to the Dominance-Prestige Account, Dominance hierarchies may emerge in childhood prior to the emergence of Prestige hierarchies, but this does not mean that the latter eventually replace the former.

\section{The Present Research}

Testing the viability of Dominance and Prestige. Several conditions must be met to properly test the Dominance-Prestige 
Account. First, we must measure the distribution of actual social influence, as well as group members' perceptions of a person's influence (Buss et al., 1987). Explicit beliefs about which tactics promote influence do not necessarily reflect the actual processes through which influence is obtained. For example, married couples rate an accommodative communication style as a useful tactic to achieve influence, but this style is, in fact, predictive of less decision-making power (Kipnis, Castell, Gergen, \& Mauch, 1976). Second, we must assess influence as it is perceived by uninvolved outside observers, as well as group members. Group members may be motivated to exaggerate (or even construct) post hoc perceptions of leaders' influence to rationalize the hierarchy that emerged (Anderson \& Kilduff, 2009b; see Jost \& Banaji, 1994). To address these issues, we assessed influence in the present research using a behavioral task, and obtained both group members' and outside observers' ratings of each group member's influence.

Third, we must ensure that Dominance is assessed in terms of actual Dominance-based on group members' reports of fear of a target individual - and not in terms of attempted Dominance. In prior work, narrow behaviors associated with Dominance (e.g., dismissive, intrusive, or contemptuous speech, nonverbal behaviors thought to convey Dominance) were found to be ineffective for rank attainment when a confederate's Dominant behavior was resisted by observers (Ridgeway, 1987; Ridgeway \& Diekema, 1989). Although these studies have been interpreted to suggest that coercion does not promote influence, they do not provide an adequate test of this question because they involved presumably failed attempts at inducing coercion; Dominant confederates did not pose any real threat to participants (either because participants resisted them or because the confederate was present only via video recording; Fiske, 1993). To address this issue, we assessed both Dominance and Prestige on the basis of peer ratings, using previously validated scales that capture the extent to which group members experience fear and admiration toward each target (Cheng et al., 2010).

Fourth, we must examine the concurrent effectiveness of Dominance and Prestige within the same social groups. A number of researchers have argued that the reason some studies found influence-attainment effects from coercive behaviors, whereas others found such effects from competence, is that the different groups examined hold different values about legitimate bases of social rank. Thus, it is critical to directly test whether the two strategies are concurrently effective within the same social groups, to examine whether (a) Dominance is effective in groups other than those that are simply uncooperative and value aggression over competence; (b) Dominance and Prestige are inherently incompatible or antagonistic; and (c) Dominant individuals and Prestigious individuals can attain high influence even when they directly compete against each other. We are aware of no prior studies that meet all these criteria.

In addition, by examining the concurrent effectiveness of the two strategies, we can also directly test the competing accounts. For example, the competence-based account of rank allocation predicts either a null or negative association between Dominance and influence, after controlling for shared variance with Prestige. Conversely, the conflict-based account predicts that rank differences should be positively associated with Dominance but unrelated to Prestige. In contrast, the Dominance-Prestige Account holds that Dominance and Prestige represent independent and distinct avenues to social rank, and thus Dominance and Prestige should each be independently associated with high social rank, even after controlling for shared variance.

Overview of studies. In Study 1 we examined whether Dominance and Prestige spontaneously emerge and coexist as viable rank-attainment strategies within the same social groups, by asking previously unacquainted individuals to complete a collaborative task and allowing social hierarchies to naturally emerge. Dominance, Prestige, and perceived influence were assessed with both within-group peer ratings and outside observers' ratings, and behavioral influence was assessed by measuring the degree to which each person shaped the group's decision making. In Study 2 we examined whether Dominance and Prestige each promote high rank within the same groups using visual attention as the barometer of rank. Observers who were unacquainted with participants from Study 1 wore an eye-tracking device while viewing video clips of the Study 1 group interactions, and we assessed the extent to which their gaze tracked targets' Dominance and Prestige, and cohered with their explicit ratings of targets' Dominance and Prestige.

\section{Study 1}

\section{Method}

Participants and procedures. One hundred ninety-one students at the University of British Columbia (53\% male) were randomly assigned to one of 36 same-sex groups (18 all-male groups, 18 all-female groups), each consisting of four to six unacquainted individuals ( $M=5.31$ participants per group). Participants were contacted prior to the study to ensure that all group members were not previously acquainted. They were paid for their participation, with the chance to earn an additional monetary bonus during the study.

Upon arrival, participants were randomly assigned seats at a rectangular table, with a name tag in front of each participant identifying him or her to other group members. Participants were first asked to privately complete the Lost on the Moon exercise (Bottger, 1984), which involves rank-ordering 15 items (e.g., oxygen tanks, heating unit, signal flares) in order of their utility for surviving a crash landing on the moon. Next, participants worked collectively as a group for $20 \mathrm{~min}$ on the same task. They were instructed to use their previously completed private responses to guide the group discussion. To incentivize group involvement, participants were told that the group's final decision would be scored against an answer key, and high scores would earn each group member a $\$ 5$ bonus. The 20-min group interaction was video-recorded with two digital video cameras mounted on tripods on either side of the table (each camera captured all participants on one side of the table and no participants on the other side; either two or three participants sat on each side; see Figure 1). Observation of the video-recorded interactions revealed that the task was engaging and evoked considerable discussion and disagreement among members.

After completing the group task, participants privately completed a posttask questionnaire in which they provided peer ratings of all group members (see below for measures), in a round-robin 


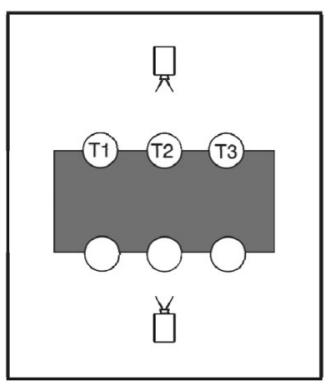

A

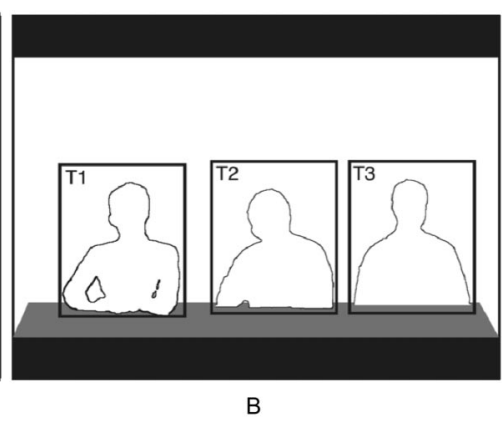

Figure 1. Set up of Study 1 group interaction (A) and example of video clip stimuli that Study 2 participants and Study 1 outside observers viewed (B). Cameras were positioned at either side of the table during the group interaction, and videos portrayed three participants (i.e., targets T1, T2, and T3) in each group. The boxes around each target in Figure 1B represent regions of interest, which were demarked to allow for the tallying of the total amount of visual attention paid to each target in Study 2. From "Gaze Allocation in a Dynamic Situation: Effects of Social Status and Speaking," by T. Foulsham, J. T. Cheng, J. L. Tracy, J. Henrich, and A. Kingstone, 2010, Cognition, 117, p. 321. Copyright 2010 by Elsevier.

design. Finally, the experimenter excused herself to purportedly score the group's submitted response on the group task.

\section{Measures.}

Posttask round-robin peer ratings. Upon completing the group task, group members rated one another on a number of dimensions (listed below), on a scale ranging from 1 (not at all) to 7 (very much). We analyzed these ratings using the software program SOREMO (Kenny, 1998), to implement the social relations model (Kenny \& La Voie, 1984). The social relations model partitions peer rating scores into perceiver, target, and relationship effects. Here we were particularly interested in target effects, which are, essentially, the average of all group members' ratings of a given target on a given dimension, after removing idiosyncratic perceiver and relationship biases and effects. ${ }^{1}$ Also of interest is target variance, which captures the amount of variation in peer ratings due to the target, and was used as an index of the degree of consensus among perceivers in their ratings of each target (i.e., a measure of interrater reliability). A larger relative target variance (i.e., target variance divided by total variance) indicates that a given target elicited a high level of consensus among group members.

Perceived social influence and agency. Participants indicated the extent to which each group member demonstrated high social influence during the task by rating each member on three items: "was paid attention," "had high status," and "led the task." All three items showed statistically significant amounts of target variance (relative target variances were $29 \%, 33 \%$, and 64\%, respectively, $p$ s $<.05,{ }^{2}$ all comparable to typically observed levels of approximately $30 \%$ relative target variance in highly visible traits such as extraversion; Kenny, Albright, Malloy, \& Kashy, 1994), indicating that group members agreed on each other's relative social influence at better than chance levels. To further partition relationship variance from error variance, these three items were subsequently entered as multiple indicators of a latent perceived social influence construct (interitem $\alpha=.89$, relative target variance $=38 \%$ ).
As an additional index of perceived influence, we also assessed perceived agency - a concept involving control, power, and status (Bakan, 1966) — which is expected to show positive associations with the two strategies. Agency was assessed with three peer-rated items culled from the Revised Interpersonal Adjective Scales: "assertive," "self-confident," and "timid" (reverse scored; Wiggins, Trapnell, \& Phillips, 1988). Statistically significant amounts of target variance were found across these three items (relative target variances were $38 \%, 41 \%$, and $40 \%$, respectively, $p \mathrm{~s}<.05$ ), so we aggregated across their target scores to form an overall score for agency (interitem $\alpha=.92$, relative target variance $=38 \%$ ).

Dominance and Prestige. To capture the extent to which each participant adopted a Dominance and a Prestige strategy, peers rated the perceived Dominance and Prestige of each group member using the Dominance and Prestige Peer Rating Scales (Cheng et al., 2010). These previously validated scales include eight items assessing Dominance (e.g., "I am afraid of him/her") and eight items assessing Prestige (e.g., "I respect and admire him/her"; see http://ubc-emotionlab.ca/research-tools/dominance-prestigescales/ for full scales; we omitted one item-"Members of your group do not want to be like him/her"- - due to its unsuitability for briefly acquainted group members). The amount of target variance in ratings across the eight Dominance items (ranging from $10 \%$ to $36 \%$ ) and across the eight Prestige items (ranging from $10 \%$ to $35 \%$ ) were statistically significant (all $p \mathrm{~s}<.05$ ), suggesting that group members could reliably report individual differences on both scales. Target scores for the eight Dominance items and the eight Prestige items were combined, respectively, to form an overall Dominance (interitem $\alpha=.93$, relative target variance $=$ $22 \%$ ) and an overall Prestige (interitem $\alpha=.89$, relative target variance $=15 \%$ ) composite for each individual.

Liking. In addition to examining the effects of Dominance and Prestige on social influence, in Study 1 we sought to probe the kinds of relationships that Dominant and Prestigious individuals have with followers, by examining whether the two strategies are differentially associated with peer liking. Our evolutionary analysis suggests that Dominance is predicated on inducing fear through coercive and intimidating behaviors, whereas Prestigious individuals have no authority or power to enforce decisions, but instead signal their kindness, warmth, and social attractiveness to maintain respect and conferred rank. We therefore expected Dominance to be negatively, and Prestige positively, associated with perceived likability. Importantly, however, we did not expect liking to promote (or inhibit) rank or influence, given that Prestigious individuals attain rank through demonstrated skills and expertise, not by gaining others' liking; and Dominant individuals attain rank from their ability to induce fear, not simply by behaving in a dislikable

\footnotetext{
${ }^{1}$ In the present context, perceiver effect quantifies the degree to which a perceiver or rater tends to perceive a consistent level of social influence across all group members. Some perceivers tend to rate all others as influential, whereas others generally see others as low in influence. Relationship effect indexes the unique relationship between two persons by measuring the degree to which a perceiver rates a given target as particularly high in influence, over and above the perceiver's general tendency to see others as influential (i.e., perceiver effect), as well as the target's tendency to be seen by all other group members as influential (i.e., target effect; Kenny, Kashy, \& Cook, 2006).

${ }^{2}$ Significance tests of variance components are conducted with onetailed tests, as variances in principle cannot be negative.
} 
fashion. Likability was assessed with two items: "I like this person" and "I like working with this person." Statistically significant amounts of target variance were found across these items (relative target variances were $15 \%$ and $22 \%$, respectively, $p \mathrm{~s}<.05$ ). Consequently, their target scores were combined to form an overall score for likability (interitem $\alpha=.89$, relative target variance $=$ $17 \%)$.

Behavioral measure of social influence. We quantified behavioral influence by assessing the degree to which individuals brought the collective group decision on the Lost on the Moon task closer to their own thoughts and opinions (Cartwright, 1959; Lewin, 1951). Specifically, following Bottger's (1984) approach, we measured the degree of similarity between each participant's private response, completed prior to the group interaction, and the group's final public, collective response. For each participant, a behavioral influence score was computed by calculating the absolute difference between his or her private ranking of each Lost on the Moon item and the group's final ranking of that item, then summing across all 15 items and multiplying by -1 (for directionality scaling). This scoring procedure can be represented as:

$$
y_{i j}=-1\left(\sum_{k=1}^{15}\left|x_{i j k}-x_{j k}\right|\right),
$$

where $y_{i j}$ is the influence score of subject $i$ from group $j, x_{i j k}$ is subject $i$ 's rating on item $k, x_{j k}$ is group $j$ 's rating on item $k$. The expression in parentheses, which captures the level of discrepancy between individual and group responses, was multiplied by -1 so that scores with a higher value (i.e., negative values closer to 0) reflect greater social influence (i.e., greater similarity between individual and group responses). The use of this behavioral measure, coupled with peers' ratings of perceived social influence, allowed us to circumvent limitations associated with sole reliance on peer reports of social influence (i.e., findings indicate that such perceptions may be only weakly correlated with actual task influence; Bottger, 1984; March, 1956).

Outside observer global judgments. Two research assistants, blind to the hypotheses and unacquainted with participants, independently watched all video-recorded group interactions. After viewing each session, they judged each participant on the following dimensions.

Perceived social influence, Dominance, and Prestige. Judges rated the extent to which each group member was "influential" (interrater $\alpha=.87$ ), "bossy and pushy" (which we used as a measure of Dominance; interrater $\alpha=.83$ ), and "respected" (which we used as a measure of Prestige; interrater $\alpha=.70$ ). Ratings were completed on a scale ranging from 1 (not at all) to 5 (extremely).

Agency and liking. Judges rated each participant on the interpersonal grid (Moskowitz \& Zuroff, 2005), a single-item instrument developed to measure observer perceptions of agentic interpersonal behaviors in a given target. By placing a single $X$ in any square on the grid, judges rated the perceived agency of each group member (interrater $\alpha=.86$ ). They also rated the extent to which each participant was successful at building friendships and alliances (interrater $\alpha=.62$ ), on a scale ranging from 1 (not at all) to 5 (very $m u c h$ ); this item was used as a measure of the extent to which each target was liked by other group members.

\section{Results and Discussion}

Do Dominance and Prestige each predict greater social influence? To test whether Dominance and Prestige each predict social influence, we examined correlations between peer-perceived Dominance and Prestige and our three indices of influence (see Table 2 for correlations among indices). When men and women were analyzed separately, the effect sizes of the association between Dominance and Prestige and the measures of social influence were almost identical; there were no significant gender differences. We thus report results based on data collapsed across genders. Both Dominance and Prestige positively predicted social influence on all three measures (see Table 3). Thus, individuals who were judged by peers to be either Dominant or Prestigious (a) were perceived by peers as possessing high influence and agency, (b) were perceived by outsider observers as possessing high influence and agency, and (c) exerted more behavioral influence over the decision-making process of the group. It is noteworthy that these correlations are based on measures of influence from three sources: (a) in-lab peers, (b) outside observers, and (c) a behavioral measure; given that only one of these measures overlaps in source with the measures of Dominance and Prestige, it is unlikely that shared method variance artificially inflated effects. Furthermore, as is shown in Table 3, this pattern of results was largely replicated when we used outside observers' perceptions of participants' Dominance and Prestige instead of in-lab peers'. The only exception was that with outside observer judgments, the positive correlation between Dominance and the behavioral measure of influence did not reach conventional levels of significance $(p=.14)$.

Are there group differences in the extent to which Dominance and Prestige promote social rank? The correlational analyses reported above cannot account for possible dependencies that may arise from groups (i.e., individuals nested within groups), violating assumptions of independently measured and uncorrelated error terms (Raudenbush \& Bryk, 2002). In addition, the influencepromoting effects of Dominance and Prestige we found may be limited to selected groups and not uniformly characteristic of most groups sampled. This is unlikely given that groups were formed via random assignment, so group differences can be expected to be minimal; indeed, most research using a small-group zeroacquaintance paradigm assumes-and has empirically verified-an absence of substantive group differences (e.g., Albright, Kenny, \& Malloy, 1988; DePaulo, Kenny, Hoover, Webb, \& Oliver, 1987; Kenny \& Albright, 1987; Kenny, Horner, Kashy, \&

Table 2

Descriptive Statistics and Correlations Among Dominance, Prestige, and Measures of Influence (Study 1)

\begin{tabular}{lrrrrrrr}
\hline \multicolumn{1}{c}{ Variable } & \multicolumn{1}{c}{$M$} & \multicolumn{1}{c}{$S D$} & 1 & 2 & 3 & 4 & 5 \\
\hline 1. Dominance & 2.34 & 0.83 & .93 & - & - & - & - \\
2. Prestige & 4.93 & 0.62 & .01 & .89 & - & - & - \\
3. Perceived influence & 4.13 & 1.12 & $.68^{* *}$ & $.57^{* * *}$ & .89 & - & - \\
4. Perceived agency & 4.63 & 1.12 & $.69^{* *}$ & $.45^{* *}$ & $.88^{* * *}$ & .92 & - \\
5. Behavioral influence & -38.16 & 13.34 & $.17^{*}$ & $.17^{*}$ & $.22^{* *}$ & $.30^{* * *}$ & - \\
\hline
\end{tabular}

Note. $N=177$. Values on the diagonal are scale alpha reliability estimates, where applicable.

${ }^{*} p<.05$. ** $p<.01$. 
Table 3

Correlations of Dominance and Prestige (as Rated by In-Lab Peers and Outside Observers) With Measures of Social Rank and Likability (Study 1)

\begin{tabular}{|c|c|c|c|c|}
\hline \multirow[b]{2}{*}{ Measure } & \multicolumn{2}{|c|}{ In-lab peer rated } & \multicolumn{2}{|c|}{ Outside observer rated } \\
\hline & Dominance & Prestige & Dominance & Prestige \\
\hline \multicolumn{5}{|l|}{ In-lab peers' ratings } \\
\hline Perceived influence & $.68^{* *}\left(.79^{* *}\right)$ & $.57^{* *}\left(.40^{* *}\right)$ & $.59^{* *}\left(.62^{* *}\right)$ & $.63^{* *}\left(.55^{* *}\right)$ \\
\hline Perceived agency & $.69^{* *}\left(.75^{* *}\right)$ & $.45^{* *}\left(.33^{* *}\right)$ & $.59^{* *}\left(.59^{* *}\right)$ & $.60^{* *}\left(.54^{* *}\right)$ \\
\hline Likability & -.06 & $.73^{* *}$ & $.13^{\dagger}$ & $.49^{* *}$ \\
\hline \multicolumn{5}{|l|}{ Outside observers' ratings } \\
\hline Perceived influence & $.57^{* *}\left(.54^{* *}\right)$ & $.38^{* *}\left(.44^{* *}\right)$ & $.70^{* *}\left(.71^{* *}\right)$ & $.73^{* *}\left(.70^{* *}\right)$ \\
\hline Perceived agency & $.56^{* *}\left(.52^{* *}\right)$ & $.35^{* *}\left(.41^{* *}\right)$ & $.69^{* *}\left(.69^{* *}\right)$ & $.64^{* *}\left(.61^{* *}\right)$ \\
\hline Likability & $-.18^{* * *}$ & $.38^{* * *}$ & .09 & $.43^{* *}$ \\
\hline Behavioral measure of influence & $.17^{*}\left(.17^{*}\right)$ & $.17^{*}\left(.22^{* *}\right)$ & $.11(.11)$ & $.13^{\dagger}\left(.14^{\dagger}\right)$ \\
\hline
\end{tabular}

Note. $\quad N=191$. Partial correlations controlling for likability are presented in parentheses.

${ }^{\dagger} p<.10 .{ }^{*} p<.05 .{ }^{* * *} p<.01$.

Chu, 1992; Malloy \& Albright, 1990). Nonetheless, to address the possibility of meaningful group differences, a two-level hierarchical linear model (HLM; Bryk \& Raudenbush, 1992) was used to test whether individuals adopting either Dominance or Prestige emerged as more influential while accounting for the nesting of participants in groups.

Intraclass correlations (ICCs) were first computed for each of the three influence indices to examine whether there was a significant amount of variability in each of these measures at the group level (i.e., the degree of nonindependence). Results indicated that group membership did not uniformly explain the variance in influence. Minimal covariation occurred within groups on perceived social influence $\left(\right.$ ICC $=7.9 \times 10^{-10}$ ) and agency $($ ICC $=$ $9.8 \times 10^{-10}$ ), suggesting an absence of between-group differences in mean influence scores. However, group membership produced clustering on the behavioral measure of influence (ICC $=.14$ ), suggesting that approximately $14 \%$ of the total variance on this measure is attributable to differences among the assigned groups. In light of this evidence suggesting some degree of clustering of social influence scores due to group membership, which may negatively bias standard errors in subsequent models employing ordinary least squares (Bliese \& Hanges, 2004; Kenny \& Judd, 1986), we tested our predictions with an HLM analytic framework to account for any nonindependence arising due to groups.

Variance in the dependent variable (i.e., influence) was partitioned into within-person and between-person components, allowing predictor terms to be represented at the level of the person (Level 1) and the level of the group (Level 2). The coefficients for Level 1 predictor terms Dominance and Prestige were modeled as random effects, to allow the effects of Dominance and Prestige on influence to vary across groups. Three models were specified to estimate the concurrent effects of Dominance and Prestige on each of the three indices of influence: peer-perceived influence, peerperceived agency, and behavioral influence. All three models shared the following formulation:

Level 1: Influence $_{i j}=\beta_{0 j}+\beta_{1 j}\left(\right.$ Dominance $\left._{i j}-\overline{\text { Dominance }_{j}}\right)$

$$
+\beta_{2 j}\left(\text { Prestige }_{i j}-\overline{\text { Prestige }}_{j}\right)+r_{i j}
$$

Level 2: $\beta_{0 j}=\gamma_{00}+\gamma_{01}\left(\overline{\text { Dominance }}_{j}\right)+\gamma_{02}\left({\overline{\text { Prestige }_{j}}}\right)+\mu_{0 j}$

$$
\begin{aligned}
& \beta_{1 j}=\gamma_{10}+\mu_{1 j} \\
& \beta_{2 j}=\gamma_{20}+\mu_{2 j}
\end{aligned}
$$

Mixed model:

$$
\begin{aligned}
\text { Influence }_{i j}= & \gamma_{00}+\gamma_{01}\left(\overline{\text { Dominance }}_{j}\right)+\gamma_{02}\left(\overline{\text { Prestige }}_{j}\right) \\
& +\gamma_{10}\left(\text { Dominance }_{i j}-\overline{\text { Dominance }_{j}}\right) \\
& +\gamma_{20}\left(\text { Prestige }_{i j}-\overline{\text { Prestige }_{j}}\right)+\mu_{0 j} \\
& +\mu_{1 j}\left(\text { Dominance }_{i j}-\overline{\text { Dominance }_{j}}\right) \\
& +\mu_{2 j}\left(\text { Prestige }_{i j}-\overline{\text { Prestige }_{j}}\right)+r_{i j}
\end{aligned}
$$

The Level 1 model expresses the influence score of person $i$ in group $j$ (Influence ${ }_{i j}$ ) as a function of his or her group $j$ 's mean influence $\left(\beta_{0 j}\right)$, and influence due to his or her Dominance $\left(\beta_{1 j}\right)$ and Prestige $\left(\beta_{2 j}\right)$ that is unique to group $j$, respectively, and a Level 1 residual term $\left(r_{i j}\right)$. Three Level 2 equations were specified: the random intercepts $\left(\beta_{0 j}\right)$, the random slopes that quantify the effect of Dominance within each group $\left(\beta_{1 j}\right)$, and the random slopes that quantify the effect of Prestige within each group $\left(\beta_{2 j}\right)$. To control for any potential effects arising from the Dominance and Prestige of fellow group members (e.g., individuals may be more influential in a group full of non-Dominant others; Dominance may be more tolerated and therefore effective in a group with Dominant others), group means on Dominance and Prestige were respectively used as predictors of the random intercept $\left(\beta_{0 j}\right)$, along with the group-level residual for the intercept $\left(\mu_{0 j}\right)$. The two random slope equations express the Level 1 regression coefficients using a grand mean of slope across all groups ( $\gamma_{10}$ and $\gamma_{20}$, respectively) and a group-specific residual $\left(\mu_{1 j}\right.$ and $\mu_{2 j}$, respectively). These error terms, $\mu_{0 j}, \mu_{1 j}$, and $\mu_{2 j}$, were respectively included to permit the influence intercepts (i.e., means), the within-group Dominance and influence slope, and the withingroup Prestige and influence slope to vary randomly across groups. All models were estimated in $\mathrm{R}$ with the nlme package (Bliese, 2012; R Development Core Team, 2006). 
In this analysis, given that our primary interest involves the effects of individuals' relative Dominance and Prestige position within their group, both Level 1 predictors of Dominance and Prestige were group mean centered (i.e., deviated around their group mean Dominance or Prestige). The within-group relationship is of interest here because we expect individuals' relative position within their group (i.e., degree to which an individual was more or less Prestigious than his or her fellow group members), rather than their absolute score, to be deterministic of rank and influence (Hox, 2010; Snijders \& Bosker, 1999). By removing all between-cluster variation from the predictor, group mean centering yields an unbiased estimate of the pooled withingroup (i.e., Level 1) regression coefficients on the key predictors of interest-individuals' relative Dominance and Prestige within group, $\gamma_{10}$ and $\gamma_{20}$-as well as a more accurate estimate of the slope heterogeneity (Bryk \& Raudenbush, 1992; Enders \& Tofighi, 2007; Hofmann \& Gavin, 1998; Kreft, de Leeuw, \& Aiken, 1995; Raudenbush \& Bryk, 2002).

We also included aggregated group means on Dominance and Prestige as covariates to account for potential contextual or compositional effects (Firebaugh, 1978; Kreft \& de Leeuw, 1998). The contextual model specified allows us to estimate the impact of grouplevel Dominance and Prestige on an individual's influence, over and above the effects of individual members' within-group standing on these two dimensions. For example, it is possible that individuals acquire greater rank and influence in groups in which others are particularly low in either Dominance or Prestige. Overall, our hypothesis was tested by examining the coefficients on individual Dominance and Prestige predictors, which represent the within-group relationship between these two strategies and each measure of influence, over and above the group's mean levels of Dominance and Prestige.

The results of all three models were consistent with our predictions in three ways (see Table 4). First, relative Dominance and Prestige each predicted greater influence across all three measures of influence: peer-perceived influence, 95\% CIs [0.95, 1.16] and $[0.89,1.16], t \mathrm{~s}(153)=20.26$ and 14.76 , both $p \mathrm{~s}<.0001$; peerperceived agency, 95\% CIs [0.99, 1.23] and $[0.72,1.03], t \mathrm{~s}(153)=$ 17.93 and 11.08 , both $p$ s $<.0001$; and behavioral influence within each group, 95\% CIs $[1.61,6.16]$ and $[0.92,7.33], t \mathrm{~s}(152)=3.37$ and $2.54, p s=.0009$ and .01 , respectively. These effects control for group mean differences on Dominance and Prestige, given that within group, group-mean-deviated Dominance and Prestige were used as predictors, and that group means on Dominance and Prestige were additionally entered to account for variability in the groups' mean-level influence. In addition, across all three models, likelihood ratio tests indicated that the covariance between Dominance and Prestige random slopes, $\tau_{12}$, was nonsignificant: perceived influence, $\chi^{2}(1)=1.35, p=.25$; perceived agency, $\chi^{2}(1)=0.54, p=.46$; and behavioral influence, $\chi^{2}(1)=0.005$, $p=.94$. These results suggest that, consistent with our expectations, Dominance and Prestige are independently associated with greater influence. That is, the efficacy of Dominance for promoting influence within a group is, on average, neither related to nor dependent on the efficacy of Prestige, and vice versa.

Second, these models revealed that Dominance and Prestige together explain the majority of variance in perceived influence $\left(R^{2}=\right.$ $.84)$ and agency $\left(R^{2}=.84\right)$, and a substantially smaller but still significant portion of variance in the behavioral measure of influence $\left(R^{2}=.12\right) .^{3}$ This is consistent with the Dominance-Prestige Account, which predicts that Dominance and Prestige represent the primary pathways to social rank, and thus together should explain the majority of the variation in rank differences among individuals.

Third, the estimated random variance components on each of the three models, which index the degree of between-group variation in the respective strengths of the relationship between Dominance and influence and between Prestige on influence, were not significantly different from zero except in one case: Dominance slopes predicting perceived influence, $\chi^{2}(1)=0.79, p=.19$; agency, $\chi^{2}(1)=4.87, p=.01$; and behavioral influence, $\chi^{2}(1)=0.02$, $p=.45$; Prestige slopes predicting perceived influence, $\chi^{2}(1)=$ $0.09, p=.38$; perceived agency, $\chi^{2}(1)=1.07, p=.15$; and behavioral influence, $\chi^{2}(1)=0.05, p=.41{ }^{4}$ Thus, by and large, slope variation across groups tended not to be greater than would be expected by chance, and groups did not differ significantly in the extent to which relative Dominance and Prestige within groups predicted influence. Individuals with greater Dominance and those with greater Prestige tended to uniformly acquire higher influence to a similar degree across groups. ${ }^{5}$

Figures $2 \mathrm{~A}$ and $2 \mathrm{~B}$ respectively illustrate the relation between within-group relative Dominance and perceived influence, and

${ }^{3}$ The relatively smaller magnitude of this coefficient of determination may have resulted from the fact that in order to be influenced, participants would not only need to agree with some other, but also need to overturn their own previous private decision, which individuals tend to resist (Mather, Shafir, \& Johnson, 2000).

${ }^{4}$ Tests of random variance components were conducted with the likelihood ratio test involving two nested models, in which the $-2 \log$ likelihood value of a reduced model containing a subset of the parameters estimated is compared with that in the full model. The difference in fit is subsequently tested with a chi-square distribution. This approach is preferred to the Wald's $Z$ statistic for accuracy, particularly in small to moderate samples (Singer \& Willett, 2003). One-tailed tests were employed in testing all variance components because variances, by definition, must always be greater than zero (Hox, 2010).

${ }^{5}$ In addition, in a more restricted model, Dominance and Prestige slopes were fixed and not permitted to vary across groups (i.e., removing $\mu_{1 j}$ and $\mu_{2 j}$ from the main model). Not surprisingly, in this model Dominance and Prestige fixed effects (i.e., $\gamma_{10}$ and $\gamma_{20}$ ) remained significant predictors of perceived influence, $\gamma_{10}=1.01,95 \%$ CI $[0.94,1.13], t(153)=22.01, p<$ .0001 , and $\gamma_{20}=1.01,95 \%$ CI $[0.88,1.14], t(153)=15.77, p<.0001$; perceived agency, $\gamma_{10}=1.07,95 \%$ CI $[0.97,1.17], t(153)=21.95, p<$ .0001 , and $\gamma_{20}=0.86,95 \%$ CI $[0.72,0.99], t(153)=12.88, p<.0001$; behavioral influence, $\gamma_{10}=3.96,95 \%$ CI $[1.68,6.24], t(152)=3.43, p=$ .0008 , and $\gamma_{20}=4.09,95 \%$ CI $[0.97,7.21], t(152)=2.59, p=.01$. We also compared the deviance estimates between this reduced model with fixed Dominance and Prestige slopes and the main model, using likelihood ratio tests (this is akin to a multiparameter test of the joint significance of the random Dominance and Prestige slopes). Results indicated that the main model containing random slopes did not provide a significant improvement in fit over the reduced model without random slopes: perceived influence, $\chi^{2}(5)=2.96, p=.71$; perceived agency, $\chi^{2}(5)=8.18, p=.15$; behavioral influence, $\chi^{2}(5)=0.83, p=.98$. Together, these results suggest that the magnitude of the two slopes, when considered together, did not vary significantly across groups, further supporting our conclusion of a lack of substantial group differences in the efficacy of Dominance and Prestige in promoting influence. However, although the inclusion of random slopes is important to control for any potential group differences in the efficacy of Dominance and Prestige, it is noteworthy that our hypothesis does not hinge on a complete absence of group differences. It is possible for the two strategies to be associated with higher rank in some groups than in others but still reveal a positive relation in most groups (potentially leading to nonzero random slope variances). Crucial to our hypothesis, and supported here empirically, is that the Dominance and Prestige fixed effects are not entirely driven by the random effects; that is, they should be positive and significant even after controlling for random slopes. 
Table 4

Model Summaries: Effects of Dominance and Prestige on Social Influence (Study 1)

\begin{tabular}{lccc}
\hline \multicolumn{1}{c}{ Parameters } & Perceived influence & Perceived agency & Behavioral influence \\
\hline & Regression coefficients (fixed effects) & \\
Intercept $\left(\gamma_{00}\right)$ & $0.25(0.84)$ & $3.82(1.27)^{* * *}$ & $-13.22(26.86)$ \\
Dominance $\left(\gamma_{10}\right)$ & $1.06(0.05)^{* * * *}$ & $1.11(0.06)^{* * * *}$ & $3.89(1.15)^{* * * *}$ \\
Prestige $\left(\gamma_{20}\right)$ & $1.03(0.07)^{* * * *}$ & $0.88(0.08)^{* * * * *}$ & $4.12(1.62)^{* *}$ \\
Group mean Dominance $\left(\gamma_{01}\right)$ & $0.25(0.11)^{*}$ & $0.15(0.17)$ & $-5.18(3.57)$ \\
Group mean Prestige $\left(\gamma_{02}\right)$ & $0.67(0.14)^{* * * *}$ & $0.09(0.22)$ & $-2.60(4.57)$ \\
\hline
\end{tabular}

Variance components (random effects)

$\begin{array}{lrrr}\text { Intercept }\left(\tau_{00}\right) & 0.02 & 0.09^{* * * *} & 29.38^{* * *} \\ \text { Dominance slope }\left(\tau_{11}\right) & 0.02 & 0.05^{*} & 0.02 \\ \text { Prestige slope }\left(\tau_{22}\right) & 0.03 & 0.06 & 4.57 \\ \text { Covariance }\left(\tau_{01}\right) & -0.01 & 0.03 & 0.03 \\ \text { Covariance }\left(\tau_{02}\right) & -0.01 & -0.01 & -9.56 \\ \text { Covariance }\left(\tau_{12}\right) & 0.02 & 0.02 & -0.02 \\ \text { Residual }\left(\sigma^{2}\right) & 0.21 & 0.19 & 135.62\end{array}$

Note. Parameter estimate standard errors are presented in parentheses. The predictors Dominance and Prestige are group mean centered.

${ }^{*} p<.05 .{ }^{* * *} p<.01 . \quad{ }^{* * * *} p<.001$.

within-group Prestige and perceived influence, across all 36 groups. Visual inspection of these figures reveals that (a) relative Dominance and Prestige within groups were each associated with greater perceived influence fairly consistently across groups, consistent with the significant positive fixed effect estimates, $\gamma_{10}$ and $\gamma_{20}$; (b) the strength of the associations was generally uniform across groups, consistent with the random slope variance estimates, $\tau_{11}$ and $\tau_{22}$; and (c) in almost all groups, the slope between Dominance and influence, and between Prestige and influence, showed a positive trend.

Are Dominance and Prestige distinct routes to social rank? Given that Dominance and Prestige were each positive predictors of all our measures of social influence, it was important to verify that they do, in fact, represent different ways of attaining rank. Notably, Dominance and Prestige were statistically independent $(r=.01, p=.85)$, consistent with the notion that they represent distinct and independent concepts. Nevertheless, to further address this issue, we next examined whether individuals high in Dominance and Prestige differed on interpersonal likability, a key dimension of social evaluation. Consistent with theoretical expectations, Prestigious individuals were viewed as highly likable by both in-lab peers and outside observers, whereas Dominant individuals were viewed as dislikable by outside observers, and neither particularly likable nor dislikable by peers. A comparison of these correlations (i.e., likability with Dominance versus Prestige) revealed that in all cases likability's association with Dominance differed significantly from that of Prestige $(Z s=-9.11,-5.05$, -6.02 , and -4.62 , respectively, all $p \mathrm{~s}<.001$; see Table 3 ). Thus, Dominance and Prestige appear to be divergent interpersonal strategies to attaining social rank. ${ }^{6}$

Does liking promote social rank? To address the question of whether interpersonal liking alone is sufficient for acquiring social influence, we correlated measures of liking with measures of social influence. In-lab peers' perceptions of participants' likability were positively correlated with their perceptions of participants' social influence $(r=.45)$ and agency $(r=.32)$, and with outside observers' perceptions of influence $(r=.29)$ and agency $(r=.25$; all $p \mathrm{~s}<.01)$.
However, likability was unrelated to behavioral influence $(r=.02, p$ $=.76$ ). Furthermore, outside observers' ratings of participants' likability were not significantly related to outside observers' perceptions of influence or agency, or in-lab peers' ratings of influence or agency, or the behavioral measure of influence ( $r$ s ranged from -.04 to $.10, p \mathrm{~s}$ ranged from .17 to .75). This discrepancy between in-lab peers' and outside observers' likability judgments may reflect the fact that in-lab peers' perceptions of participants' likability were, to some extent, post hoc constructions formed to rationalize the hierarchy that emerged (M. T. Lee \& Ofshe, 1981; Sherman, 1983). This is based on the assumption that outside observers would not be motivated to view high-ranking group members as likable, whereas group members themselves must, in a sense, "live with" the hierarchy that emerged, as well as the finding that behavioral influence was unrelated to likability ratings from either set of perceivers. These findings also lend support to theories that conceptualize influence as orthogonal to liking (Coie et al., 1982; Foa \& Foa, 1974; Wiggins \& Trapnell, 1996).

\footnotetext{
${ }^{6}$ To examine whether Dominance and Prestige interact to predict influence (e.g., is the highest social rank found among individuals who adopt both strategies simultaneously?), we fitted three HLM models associated with the outcome variables of perceived influence, perceived agency, and behavioral measure of influence. As in the HLM models presented above, group-mean-centered Dominance and Prestige were entered as Level 1 predictors; group's mean Dominance and Prestige were entered as Level 2 predictors of the group intercept; and the intercept, Dominance slope, and Prestige slopes were modeled as random effects. In these models, we additionally entered the interaction of (group-mean-centered) Dominance and Prestige, $\beta_{3 j}\left[\left(\right.\right.$ Dominance $\left._{i j}-\overline{\text { Dominance }_{j}}\right) \times\left(\right.$ Prestige $\left.\left._{i j}-\overline{\text { Prestige }_{j}}\right)\right]$ as a Level 1 predictor, and its effect was allowed to vary randomly across groups. We found no evidence for any substantive interactive effects; the interaction term in all three models did not differ significantly from zero at conventional levels of significance-perceived social influence, $\gamma_{30}=$ $0.13,95 \%$ CI $[-0.06,0.33], t(152)=1.39, p=.17$; perceived agency, $\gamma_{30}=-0.18,95 \%$ CI $[-0.40,0.05], t(152)=-1.54, p=.13$; behavioral influence, $\gamma_{30}=-1.53,95 \%$ CI $[2.99,-6.05], t(151)=-0.66, p=$ .51 -and all these nonsignificant interaction effects were clearly much smaller than the significant main effects.
} 
A
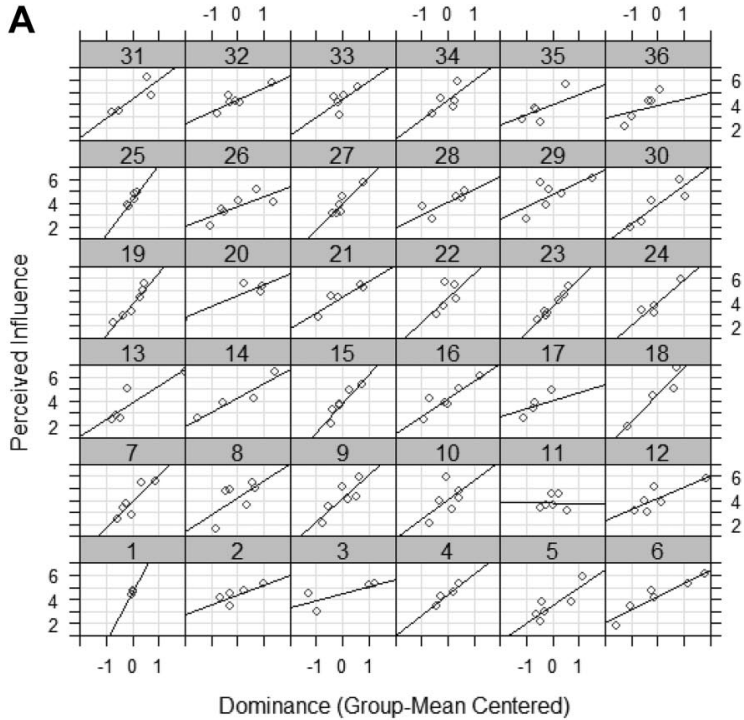

B

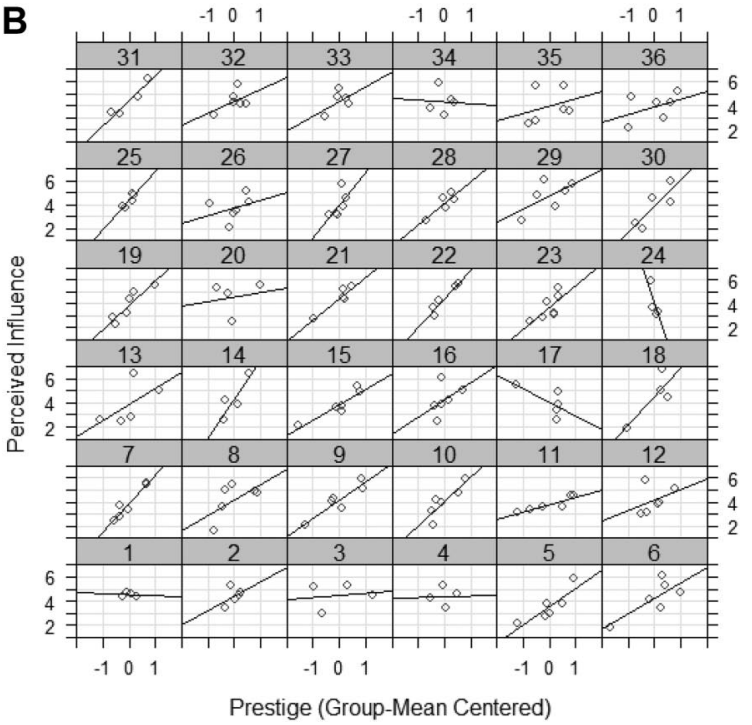

Figure 2. (A) Scatterplots of perceived social influence as a function of relative Dominance for each of the 36 groups. Group number is labeled above each panel (Groups 1-18 are composed of all male participants, and Groups 19-36 are all female). On average, across groups, relative Dominance within group (computed by group-mean centering Dominance target effects) predicted greater perceived influence, $\gamma_{10}=1.05,95 \%$ CI $[0.95,1.16], t(153)=20.26, p<.0001$. These plots reveal a positive relationship between relative Dominance and perceived influence in all but one group (Group 11). No significant gender differences emerged. (B) Scatterplots of perceived social influence as a function of relative Prestige for each of the 36 groups. Group number is labeled above each panel (identical to above, Groups 1-18 are composed of all male participants, and Groups 19-36 are all female). On average, across groups, relative Prestige within group (computed by group-mean centering Prestige target effects) predicted greater perceived influence, $\gamma_{20}=1.03,95 \%$ CI $[0.89,1.16], t(153)=14.76, p<.0001$. These plots reveal a positive relationship between relative Prestige and perceived influence in 31 of the 36 groups (and not in Groups 1, 4, 17, 24, and 34). Inspection of the panels associated with these groups indicates that they have restricted variability on either one or both variables, which may explain the absence of a positive slope in these groups. No significant gender differences emerged.
Nonetheless, to more conclusively rule out the possibility that the associations of Dominance and Prestige with social influence were driven by liking, we next computed partial correlations between peer-rated Dominance and Prestige and the three measures of influence, controlling for peers' liking. As is shown in Table 3 (in parentheses), all effects held controlling for liking, suggesting that likability is neither necessary for the attainment of rank nor sufficient, according to outside observers' perceptions of influence and the behavioral measure of influence.

Summary. Study 1 suggests that Dominance and Prestige are each effective routes to social rank. This finding emerged from three kinds of data: (a) ratings of Dominance, Prestige, and social influence from in-group peers; (b) ratings of Dominance, Prestige, and social influence from outside observer judges; and (c) a behavioral measure of influence. Importantly, the association between each strategy and influence did not differ significantly across groups, consistent with the notion that, on average, Dominance and Prestige concurrently promote social rank uniformly across groups. Thus, by and large, slope variation across groups was not greater than would be expected by chance, and groups did not differ significantly in the extent to which relative Dominance and Prestige within groups predicted influence. Individuals with greater Dominance and those with greater Prestige tended to uniformly acquire higher influence to a similar degree across groups. These relations held while controlling for how much participants were liked, suggesting that the effectiveness of Dominance and Prestige in obtaining social rank cannot be attributed to effects of these strategies on targets' likability; and, in fact, Dominance and Prestige seemed to have completely opposite effects on likability.

\section{Study 2}

In Study 2, we tested whether the allocation of visual attention-a social outcome described as "the best framework for analyzing social rank as it takes into account all leadership styles" (Hold, 1976, p. 179; see also Chance, 1967; Fiske, 1993)-is associated with either Dominance or Prestige. Despite a theoretical emphasis on visual attention as an indicator of social rank, we are aware of only two prior studies that examined whether rank is associated with the reception of greater visual attention in adults. In one study, observers wearing an eye-tracking device were found to selectively attend to photos of individuals displaying cues of Prestige (i.e., males in professional attire); Dominance was not examined (Maner, DeWall, \& Gailliot, 2008). In the other study, individuals who were rated by other group members as "leading the task" were found to receive the most visual attention from unacquainted observers who wore an eye-tracking device while viewing video recordings of the group interactions (Foulsham, Cheng, Tracy, Henrich, \& Kingstone, 2010). Neither of these studies separately examined Dominance and Prestige, so it remains unclear whether each strategy results in greater visual attention. Theoretically, Dominants may be visually tracked out of fear of unexpected attacks (though direct eye contact may be avoided in cases where Dominants can notice others' stares, which could signal a challenge; Exline, Ellyson, and Long, 1975; Mazur \& Booth, 1998), and Prestigious individuals may be carefully monitored to facilitate learning and copying.

The goal of Study 2 was to determine whether gaze allocation patterns corresponded to perceived Dominance and Prestige. By 
using the video-recorded interactions from Study 1 as stimuli in Study 2, we were able to measure visual attention received by individuals in a group with demonstrated Dominance and Prestige hierarchies, and test how eye-tracked participants' attention varies as a function of targets' Dominance and Prestige. A final novel feature of Study 2 is that because we assessed perceived Dominance and Prestige by obtaining ratings from eye-tracked participants who had only very limited exposure to targets (see Method), we were able to examine whether these judgments can be made accurately with only minimal information.

\section{Method}

Participants and procedures. Fifty-nine undergraduates at the University of British Columbia (61\% female) participated in exchange for course credit. All participants were unfamiliar with the target individuals in the video stimuli.

Participants were instructed to watch a series of six 20-s video clips portraying three people working together on the group task described in Study 1 (see Figure 1 for a schematic). Participants were told, "Imagine that you're in the room with these people, working on the task. Please think about which of the people in the group you would want to work with in a subsequent task." These instructions were given to prompt participants to view the video clips in a similar frame of mind as the individuals featured in the clips. While wearing an eye tracker, participants then viewed the six clips (of the same group of three targets) in a randomly determined order (i.e., nonchronological), to prevent them from discerning Dominance and Prestige on the basis of the sequential content of the interactions, and instead encourage them to focus them on targets' verbal and nonverbal behaviors within each clip. The video clips were shown on a 19-in. (48.26-cm) computer monitor with a refresh rate of $60 \mathrm{~Hz}$. Participants used a headrest, which minimized head movements and ensured a constant viewing distance of $60 \mathrm{~cm}$, which resulted in a screen size of $40^{\circ}$ by $31^{\circ}$ of visual angle. Sound was played through a pair of speakers positioned on either side of the monitor. The Eyelink II system was used to record participants' eye movements with a head-mounted camera. Pupil position was recorded monocularly from the video image of the right eye at $500 \mathrm{~Hz}$.

At the beginning of each of the six clips, a drift-correct marker was presented in the center of the screen, and participants were required to look at the dot and press a key on the keyboard when central fixation was attained. The clip then appeared, and video and audio were played at normal speed for the 20-s duration. Eye movements were recorded during this time, along with a record of time stamps indicating the onset time of each frame of the video.

After viewing all six clips, participants rated the perceived Dominance, Prestige, perceived social influence, and likability of each of the targets in the clips using the same scales as were completed by in-lab peers in Study 1.

Upon completion of all data collection, a research assistant viewed all 24 clips at reduced speed and logged the beginning and end of each utterance or verbalization made by each target. This was repeated three times per clip (once for each target), to accurately assess the total number of seconds each target spoke. Speaking duration times were subsequently divided by the length of each associated clip (i.e., $20 \mathrm{~s}$ ), to determine the proportion of time within each clip each target was speaking, then aggregated across the six clips to determine each target's overall mean proportion of speaking time. Speaking time was subsequently entered into analyses as a covariate, given our expectation that it would significantly affect Dominance, Prestige, and visual attention.

Stimuli. Four sets of video clips portraying a trio of Study 1 participants completing the group decision-making task were selected from all available clips on the basis of relative Dominance and Prestige ratings (made by in-lab peers in Study 1) of the targets. Given our goal of testing whether highly Dominant individuals and highly Prestigious individuals are likely to receive greater visual attention from onlookers compared with individuals who score low on either dimension, we wanted to ensure that each video clip featured individuals who differed substantially from each other in perceived Dominance and Prestige. Indeed, across the four sets of videos, there was a significant difference in in-lab peer-perceived Dominance (based on Study 1) between targets with the highest score $(M=4.77)$ and those with the lowest score $(M=2.04), d=4.59, t(6)=6.49, p=.00064$; and a significant difference in in-lab peer-perceived Prestige between targets with the highest score $(M=5.76)$ and those with the lowest score $(M=4.45), d=2.40, t(6)=3.40, p=.02$.

Participants viewed six clips, each $20 \mathrm{~s}$ in length, from each of the four video sets. These were selected by a research assistant blind to research hypotheses who was instructed to select segments during which a key decision was made by the group. Each participant viewed clips of only one set of targets (i.e., six clips from the interaction).

\section{Results and Discussion}

Data-analytic approach. To determine the amount of visual attention participants paid to each target, a region of interest (ROI) was defined around each target, at a consistent size of $10.9^{\circ}$ by $14.1^{\circ}$ (see Figure 1 ). Fixations landing within a target's prescribed ROI were classified as attention allocated to that target. Two indices of attention-mean proportion of fixations out of the total number of fixations made and total fixation duration-were computed for each participant. Mean proportion of fixations was computed by dividing, for each participant, the total number of fixations that fell within a given target's ROI by the total number of fixations that occurred during the 20-s clip, averaged across all six clips. Total fixation duration was computed by taking, for each participant, the sum duration of all the fixations (in seconds) on a given target's ROI, across all six clips. This index reflects differences in the total length of time participants gazed at each target, over and above the number of fixations, and is thus qualitatively distinct from the proportion of fixations index.

For each index of attention, our study design yielded three observations for each participant-one for each of the three targets in each clip. These three attention scores were grouped and nested within each participant, potentially leading to a lack of independence for individual observations within subjects, and thus violating assumptions of independence and homoscedasticity in ordinary least-squares-based approaches (Bliese \& Hanges, 2004; Kenny \& Judd, 1986). Indeed, ICCs indicate a high degree of covariation among observations within each participant cluster for the mean proportion of fixations index $(\mathrm{ICC}=-.32)$ and the total fixation duration index (ICC $=$ 
$-.30) .^{7}$ Thus, to account for the nonindependence between observations produced by such nesting, clustered robust standard errors were used to derive accurate estimates of standard errors (Wooldridge, 2003).

Do Dominant individuals and Prestigious individuals each receive greater visual attention? We conducted two multiple regression analyses predicting each index of attention (proportion of fixations and total fixation duration) on eye-tracked participants' ratings of each target's perceived Dominance and Prestige and two control variables: target speaking time and seating position (i.e., whether the target was assigned to sit in the left, right, or center position at the table). To facilitate interpretation, all predictors were grand mean centered, with the exception of seating position, which was dummy coded (as 0 for side or 1 for center; our assumption was that the center-seated target might receive greater attention than the other two due to his or her position). ${ }^{8}$ In all models, we used clustered robust standard errors, clustering on participants because the analyses compiled repeated observations from the same eye-tracked participants, who each provided multiple observations.

Table 5 presents the two regression models. After controlling for eye-tracked participants' judgments of target's Prestige, speaking time, ${ }^{9}$ and seating position, the regression coefficients for Dominance were statistically significant and positive in both models, indicating that a 1-point increase in perceived Dominance was associated with a $2 \%$ increase in proportion of fixations and 2.11 additional seconds of total fixation duration. Similarly, controlling for targets' perceived Dominance, speaking time, and seating position, the regression coefficients for Prestige were significant and positive in both models, indicating that a 1-point increase in perceived Prestige was associated with a $2 \%$ increase in proportion of fixations and an additional 1.94 $\mathrm{s}$ of total fixation duration.

In both models, speaking time and seating position also emerged as significant predictors, suggesting that these factors also influenced attention, as expected based on previous research (Aries, Gold, \& Weigel, 1983; Cashdan, 1998; Cohen, 1994; Mast, 2002; Mullen, Salas, \& Driskell, 1989). Speaking time was also positively associated with eye-tracked judges' perceptions of Dominance $(r=.68)$ and Prestige $(r=.35)$. There were no perceiver gender or target gender main or interactive effects.

If Dominance and Prestige represent the primary pathways to social rank, the two strategies together should explain substantial portions of variance in attention. To test this prediction, we next ran separate regression models with proportion of fixations and total fixation duration as outcomes and eye-tracked judges' ratings of Dominance and Prestige as predictor variables - here the two predictor variables showed a small positive association (using clustered robust standard errors), $\beta=.20, t(58)=2.86, p=.0059$-after standardizing all variables. Again, clustered robust standard errors were used. As expected, Dominance and Prestige were each significantly associated with both measures of attention: proportion of fixations, $\beta \mathrm{s}=.56$ and $.24, t \mathrm{~s}(58)=7.79$ and $3.72, p s<.001$; and total fixation duration, $\beta \mathrm{s}=.55$ and $.23, \mathrm{ts}(58)=7.03$ and $3.36, p \mathrm{~s}<.01$. Furthermore, perceived Dominance and Prestige explained considerable amounts of variance in proportion of fixations $\left(R^{2}=.48,95 \% \mathrm{CI}[.31, .65]\right)$ and total fixation duration $\left(R^{2}=.46,95 \%\right.$ CI $\left.[.28, .64]\right)$. Together, these results suggest that Dominance and Prestige were each strongly associated with the reception of greater visual attention, and these effects were independent of how much targets spoke and where they sat.

To ensure that eye-tracked judges' perceptions of targets' Dominance and Prestige was accurate, we next examined correlations between these judges' ratings of targets and those made by Study 1 in-lab peers, on these dimensions. Results indicated that the two sets of viewers showed substantial agreement in their ratings of targets' Dominance and Prestige $(r s=.79$ for Dominance and .66 for Prestige, $p \mathrm{~s}<.05$; note that these correlations were conducted across the 12 targets, not across participants). These correlations are particularly noteworthy given that the two sets of participants had access to substantially different amounts of information and made their ratings after engaging in very different tasks (i.e., viewing and interacting with targets face to face for $20 \mathrm{~min}$ with the goal of completing a collaborative task, versus viewing targets on video for a total of $120 \mathrm{~s}$ truncated into fragmented and randomized 20-s segments, while "imagining" that they were interacting with them). This high level of convergence suggests that both sets of perceptions were valid measures of targets' use of Dominance and Prestige strategies. Furthermore, these correlations also suggest that even under conditions of limited exposure, observers can make highly accurate judgments of Dominance and Prestige. ${ }^{10}$

Does liking promote social attention? To examine whether the effects of Dominance and Prestige on visual attention might be due to targets' likability, we next separately regressed each

\footnotetext{
${ }^{7}$ Negative empirical estimates (and population values) of the ICC can arise when the average covariance among the items is negative (Shrout \& Fleiss, 1979), reflecting the bounded nature of the data here; that is, greater visual attention to one target would necessarily lead to less attention to other targets (see Kenny et al., 2006, p. 33, for a similar example).

${ }^{8}$ We also ran analyses with two dummy codes representing the three seating positions (left, center, or right). In all models, there was no significant effect of left versus right seating position. In addition, all results reported below held when three dummy variables were entered as covariates in the models to account for any potential differences due to the four clip sets used.

${ }^{9}$ It is noteworthy that controlling for speaking time is a conservative approach to testing the effects of Dominance and Prestige on attention. Theoretically, Prestigious individuals should be deferred to and invited to speak (by subordinates who wish to acquire their skills and knowledge), whereas Dominant individuals should forcefully occupy discussions. Thus, increased speaking time is a theoretically predicted effect endogenous to Dominance and Prestige processes, and not necessarily a confound. Nonetheless, by controlling for speaking time, we were able to ensure that differences found were not entirely attributable to how much each target spoke.

${ }^{10}$ Of note, we could not directly test whether eye-tracked participants attention covaried with targets' Dominance and Prestige as judged by in-lab peers from Study 1 because there were too few observations on the dependent variable; only 12 Dominance or Prestige in-lab peer-rated scores were available. Though we considered converting the Study 1 continuous peer ratings into relative Dominance and Prestige categorical ranks and using analysis of covariance to address this issue, we realized this was not possible because of the naturalistic design of the study. Targets were not seated according to their Dominance or Prestige ranks (since these emerged only afterward), so the three factors of Dominance, Prestige, and seating position (the last of which must be included as a covariate, given the natural tendency for center-seated targets to receive the greatest visual attention) were not fully crossed at each level. In fact, no targets (and thus observations) were available in the following cross-tabulated cells: lowDominance, center-seating position; and medium-Prestige, center-seating position.
} 
Table 5

Linear Regressions Predicting Visual Attention From Eye-Tracked Participant-Rated Dominance and Prestige, Controlling for Speaking Time and Seating Position (Study 2)

\begin{tabular}{|c|c|c|c|c|c|c|c|c|}
\hline \multirow[b]{2}{*}{ Predictor variable } & \multicolumn{4}{|c|}{ Proportion of fixations } & \multicolumn{4}{|c|}{ Total fixation duration (s) } \\
\hline & $b$ & $S E$ & $\beta$ & $t$ & $b$ & $S E$ & $\beta$ & $t$ \\
\hline Dominance & 0.02 & 0.01 & .18 & $2.47^{*}$ & 1.60 & 0.76 & .17 & $2.11^{*}$ \\
\hline Prestige & 0.02 & 0.01 & .16 & $3.09^{* *}$ & 1.94 & 0.73 & .15 & $2.65^{*}$ \\
\hline Speaking time & 0.43 & 0.05 & .48 & $8.97^{* * *}$ & 53.69 & 6.63 & .49 & $8.09^{* * *}$ \\
\hline Position $^{\mathrm{a}}$ & \multirow{2}{*}{\multicolumn{4}{|c|}{.66}} & 6.11 & 1.84 & .44 & $3.32^{\text {*** }}$ \\
\hline$R^{2}$ & & & & & \multicolumn{4}{|c|}{.64} \\
\hline
\end{tabular}

Note. $\quad N=177$. Clustered robust standard errors were used to adjust for nonindependence of observations resulting from repeated observations from the same participants, 59 individuals (clusters).

${ }^{a}$ Individual level dummy coded: $0=$ seating on the left or right side, $1=$ center position

${ }^{*} p<.05 .{ }^{* * *} p<.01$.

of the two attention indices on eye-tracked participants' ratings of targets' likability, Dominance, and Prestige, as well as speaking time and seating position. As in the previous models, all variables were standardized, and clustered robust standard errors were used to account for the nonindependence of observations in the outcome variables. In both models, all predictor variables-except for perceived likability: $\beta=-.03, t(58)=$ $-0.37, p=.71$, for proportion of fixations, and $\beta=-.00$, $t(58)=-0.01, p=.99$, for total fixation duration-significantly predicted the distribution of attention. Thus, after controlling for likability, speaking time, and seating position, perceived Dominance was still associated with an increase in proportion of fixations, $\beta=.17, t(58)=2.18, p=.03$, and total fixation time, $\beta=.17, t(58)=2.06, p=.04$, as was perceived Prestige, with proportion of fixations, $\beta=.18, t(58)=2.26$, $p=.03$, and total fixation time, $\beta=.15, t(58)=1.96, p=.05$. Thus, the increased social attention received by highly Dominant targets and highly Prestigious targets cannot be attributed to how much these targets were liked or disliked, and in fact, the extent to which targets were viewed as likable did not affect the amount of attention they received.

\section{General Discussion}

The primary aim of the current research was to examine whether Dominance and Prestige are distinct yet viable avenues to attaining social rank. Using a multimethod approach-in which social rank was operationalized as both in-lab peers' and outside observers' perceptions of social influence, as well as actual, behavioral influence over decision making in a collaborative task-Study $1 \mathrm{dem}-$ onstrated that individuals high in Dominance and those high in Prestige (as rated by in-lab peers and outside observers) tend to receive greater influence during a group task. Study 2 replicated this finding with rank operationalized as social attention; highly Dominant group members and highly Prestigious group members tend to receive greater visual attention from outside observers than their counterparts who are low on both dimensions. This result was replicated across two measures of visual attention and two sources of Dominance and Prestige perceptions, and held controlling for speaking time and seating position. Together, these two studies provide evidence for the central claim of the Dominance-Prestige Account: Dominance and Prestige are each effective strategies for attaining social rank in contemporary human groups, even when
Dominant and Prestigious individuals directly compete for rank within the same group.

Although previous studies have identified distinct microlevel personality traits and attributes that are associated with Dominance or Prestige (Buttermore, 2006; Cheng et al., 2010; Johnson et al., 2007; Reyes-García et al., 2008), this is the first research to examine the concurrent efficacy of the two strategies for attaining rank and influence. In addition, whereas previous work examined long-term Dominance and Prestige hierarchies in preexisting social groups, the present research demonstrates that both hierarchies emerge rapidly among members of short-term, newly acquainted groups who interact for only $20 \mathrm{~min}$. The finding that differences along both dimensions emerged spontaneously and reliably in brief social encounters, and that individuals' ranks on each dimension were readily apparent to peers within the group, outside observers, and eye-tracked observers who viewed each interaction for only $120 \mathrm{~s}$ of fragmented moments, suggests that individual differences in the use of these strategies are fundamental to interpersonal relationships, and that individuals are highly attuned to accurately perceiving these differences.

These findings are also consistent with a large body of research demonstrating high levels of consensus and accuracy in person judgments from only brief observations of "thin sliced" behavior (e.g., Ambady \& Rosenthal, 1992; Funder \& Colvin, 1988). The present research adds to this literature by demonstrating that Dominance and Prestige, too, can be very quickly and accurately judged. This ability may be shaped by selection pressures on subordinates to monitor and preempt attacks from Dominants and maximize opportunities to acquire fitness-enhancing cultural information from Prestigious individuals. Study 2 suggests that, in both cases, these quick perceptual abilities may be facilitated by automatic visual attention patterns.

\section{Implications for the Evolutionary Foundations of Human Social Hierarchy}

The finding that Dominance and Prestige can coexist within social groups as viable rank-promoting strategies suggests that human social hierarchies are multidimensional. In particular, we found that Dominance is predictive of influence even after controlling for Prestige, suggesting that Dominant individuals do not acquire influence by merely invoking misperceptions of high competence and ability, or by demonstrating social attractiveness (cf. 
Anderson \& Kilduff, 2009b; Sadalla, Kenrick, \& Vershure, 1987). This finding stands in contrast to the competence-based perspective, which maintains that intimidation and aggression are largely ineffectual for rank attainment, and that competence and generosity represent the primary routes to influence (e.g., Anderson \& Kilduff, 2009a, 2009b; Barkow, 1975; Ridgeway \& Diekema, 1989). Our findings also challenge the conflict-based account of hierarchy, which holds that individuals generally acquire rank by displaying Dominance and threat, and underemphasizes the importance of abilities and competence. By supporting the Dominance-Prestige Account, the present findings integrate these two narrower accounts, and thus reconcile a long-standing division in the literature on human social hierarchies. When considered jointly, Dominance and Prestige explain a substantial portion of variation between individuals in social rank, consistent with the theoretical notion that the two strategies form the core foundations of human hierarchical relations.

These findings also suggest that many of the fairly wide range of narrow attributes and behaviors previously found to be associated with social rank likely captured one of the two fundamental strategies. Specifically, prior evidence for an association between rank and physical strength (Schjelderup-Ebbe, 1935), aggression (Griskevicius et al., 2009), toughness (Cashdan, 1998), threatening and coercive behavior (Kyl-Heku \& Buss, 1996), assertiveness (Gibb, 1968; Lord et al., 1986; Stogdill, 1948), need for power (Flynn, Reagans, Amanatullah, \& Ames, 2006; Winter, 1988), anger (Tiedens, 2001; Van Kleef, Homan, Beersma, \& van Knippenberg, 2010), narcissism (Brunell et al., 2008), and prioritizing self- over group interest (Maner \& Mead, 2010) may be more parsimoniously viewed as reflecting Dominance-based processes. Likewise, evidence for an association between rank and the possession of valuable skills (Berger et al., 1972; Ellis, 1994; Lord et al., 1986), task ability (Driskell et al., 1993), intelligence (Lord et al., 1986; Stogdill, 1948), perceived competence (Anderson \& Kilduff, 2009b), specialized knowledge (Mesoudi, 2008; Van Vugt, 2006), altruism (Hardy \& Van Vugt, 2006; Willer, 2009), helpfulness (Flynn et al., 2006), generosity, honesty, responsibility, fairness (Lord \& Maher, 1991), and charisma (Awamleh \& Gardner, 1999) may in fact reflect Prestige processes. The present research is the first to conceptually bring together these seemingly disparate sets of findings into one coherent model and to provide an empirically supported account that suggests that the competence-based and conflict-based perspectives are not in fact incongruous, but rather that human hierarchical relations are dual faceted.

Distinctions similar to Dominance and Prestige have been made in psychology (e.g., Gilbert, Price, \& Allan, 1995; Magee \& Galinsky, 2008), sociology (e.g., Kemper, 1990), anthropology (e.g., Barkow, 1975; Krackle, 1978), and zoology (Chance \& Jolly, 1970) based on inductive inferences. However, the framework adopted here has several advantages over these earlier models. First, it explains why subordinates in human social groups seem to demonstrate two notably distinct ethological and psychological patterns directed at different high-ranking individuals-copying and deferring to some leaders while avoiding and fearing others, as well as differential patterns of imitation, memory, attention, and persuasion in the presence of these different leaders (for a review, see Henrich \& Gil-White, 2001). Second, it explains why certain socially attractive qualities (e.g., expertise and success) promote rank. Third, it can account for group and cultural differences in the traits and abilities that lead to high rank; for example, why athletic ability is valued among adolescent boys but not academic scholars. In sum, by positing a cultural learning process to account for Prestige hierarchies and employing evolutionary logic, the Dominance-Prestige Account provides a basis for understanding the distal forces that shape preferences for social models and processes of social influence.

More broadly, our findings lend support to the theoretical account of Prestige as having arisen in response to the evolution of cultural learning capacities in humans. With the emergence of capabilities for acquiring cultural information, it likely became adaptive for individuals to acquire such knowledge from skilled social models, resulting in a human psychology in which individuals ingratiate themselves to skilled others by displaying deference. This in turn permits subordinate learners access to Prestigious models, who allow copying and thus exert further influence over learners. Consistent with this account, our results indicate that individuals pay greater attention to Prestigious others than nonPrestigious, and defer to their opinions (as evidenced by the finding that Prestigious individuals scored higher on the behavioral measure of influence in Study 1), despite our finding that these individuals, in contrast to Dominants, are not viewed as threatening and are well liked. The present findings are thus compatible with the theory of Prestige as resulting from the evolution of cultural transmission (see Boyd \& Richerson, 1985; Henrich \& Gil-White, 2001); in our view, this account provides the most parsimonious and empirically supported framework for the extant data.

The present findings also raise questions for accounts of human social hierarchy as being exclusively Prestige-based, having evolved (or "exapted") from earlier Dominance hierarchies seen in other animals (Barkow, 1975). Given the evidence that emerged here for the prevalence and viability of Dominance, it seems reasonable to conclude that human social stratification is characterized by the co-occurrence of both strategies, even among groups of university students who are presumably more oriented than average toward the attainment of cultural knowledge, and not particularly fearful of threat of force in a laboratory-based situation. Given the importance of agonistic contests in virtually all nonhuman animal social hierarchies (Mazur, 1973), Dominance in humans likely represents an evolutionarily ancient system that, despite the rise of Prestige, remains operative. Human Dominance is not, however, limited to physical conflict; in most contemporary societies it is likely more frequently wielded by controlling costs and benefits in nonagonistic domains.

One potentially unique feature of human hierarchies is that merit-based institutional positions, which are attained via the demonstration of skill and ability, are typically endowed with the control of costs and benefits, and thus can evoke Dominanceoriented behaviors, resulting in the simultaneous use of both strategies (see also Magee \& Galinsky, 2008). Indeed, in the present as well as previous research (Cheng et al., 2010), Dominance and Prestige were statistically independent, suggesting that individuals could concurrently adopt both strategies, consistent with developmental studies showing that some children simultaneously demonstrate both prosocial and coercive relational styles (Hawley, Little, \& Pasupathi, 2002). 
Finally, the present research also has implications for research on the evolutionary origins of leadership (e.g., Gillet, Cartwright, \& Van Vugt, 2011; Van Vugt, 2006). Although we focused more on rank and influence than leadership, effective leadership depends on inducing social influence (Bass, 1990; Hollander, 1985; Hollander \& Julian, 1969), suggesting that Dominance and Prestige may also underpin two alternative styles of leadership. In keeping with this notion, researchers have delineated two contrasting leadership personalities, termed selfish and servant (Gillet et al., 2011; Greenleaf, 2002; D. S. Wilson, Van Vugt, \& O'Gorman, 2008). Selfish leaders have been found to exploit their positions of power and take more than followers from a common resource, out of feelings of entitlement. Their behaviors contrast sharply with those of servant leaders, who engage in self-sacrificial, altruistic behaviors to promote group cooperation at a cost to themselves (de Cremer \& van Dijk, 2005; Gillet et al., 2011; O’Gorman, Henrich, \& Van Vugt, 2009). A similar distinction can be found in studies comparing autocratic and democratic approaches to leadership (Lewin, Lippitt, \& White, 1939).

Our findings also shed light on the prevalence of narcissistic, aggressive, and manipulative egotists in leadership roles, such as company presidents and chief executive officers (Brunell et al., 2008; Deluga, 1997; Fast \& Chen, 2009; Rosenthal \& Pittinsky, 2006; Van Vugt, 2006; Wasylyshyn, 2005; Workplace Bullying Institute \& Zogby International, 2010), and the multitude of kings, emperors, tyrants, and dictators who have throughout history exploited their leadership positions for self-benefit at the cost of the group (Betzig, 1993). The influence of these despots may be explained by their effectiveness in deploying a Dominance strategy. These individuals may rely on Dominance-oriented behaviors as a result of insecurities about their ability to attain broadly recognized Prestige; indeed, recent findings suggest that powerful individuals become aggressive when they perceive themselves as incompetent (Fast \& Chen, 2009).

\section{Limitations and Future Directions}

One limitation of the present research is our reliance on a correlational approach, which prevents us from directly addressing questions of causality-whether Dominance and Prestige are causal antecedents to social rank. However, given that Dominance and Prestige are latent perceptions constituted from the sum of numerous more specific social attributes, behaviors, and interpersonal traits, manipulating any single attribute would likely be ineffective to promote a genuine, believable Dominant or Prestigious reputation in a face-to-face context. Nevertheless, one important future direction is to directly test the causal model indicated by our theoretical account.

Another important direction is to examine whether the present findings generalize to stable long-term groups. Previous research suggests that both dimensions exist and can be reliably assessed within such groups (Cheng et al., 2010; Reyes-García et al. 2008, 2009), and that in at least one long-term group (university athletic teams), Dominant individuals and Prestigious individuals are both perceived as leaders by other group members (Cheng et al., 2010). Thus, it seems likely that the present results represent Dominance and Prestige dynamics as they occur in real-world, long-term social hierarchies, but this should be tested in future research.
Given the evolutionary framework of the present research, another limitation is our inclusion of only North American undergraduates, who are often not representative of most of the world's populations (Henrich, Heine, \& Norenzayan, 2010). Future studies are needed to replicate these findings in diverse populations, to test whether the rank-promoting effects of Dominance and Prestige generalize across human societies. Previous research is consistent with this expectation-Dominance and Prestige hierarchies have been documented in culturally and geographically diverse populations, including the Tsimane, a highly egalitarian population of forager-horticulturalists in the Bolivian Amazon (Reyes-García et al., 2008, 2009; see also von Rueden et al., 2008), as well as industrialized populations from the United States and Canada (Buttermore, 2006; Cheng et al., 2010; Johnson et al., 2007)—but these studies have not tested whether each of the two strategies, defined in terms of higher order, widely encompassing reputations, is associated with social rank and influence in these diverse groups.

In conclusion, although the pursuit of social rank is a recurrent, pervasive, and universal feature of human societies, only recently has a parsimonious evolutionary account emerged that can unify the diverse and seemingly contradictory empirical findings regarding rank attainment. The present research provides support for the Dominance-Prestige Account, and demonstrates that though both are effective strategies for ascending the social hierarchy, they are underpinned by divergent interpersonal behaviors and perceptions.

\section{References}

Abramovitch, R. (1976). The relation of attention and proximity to rank in preschool children. In M. R. A. Larsen \& R. R. Larsen (Eds.), The social structure of attention (pp. 153-176). London, England: Wiley.

Abramovitch, R., \& Grusec, J. E. (1978). Peer imitation in a natural setting. Child Development, 49, 60-65. doi:10.2307/1128593

Albright, L., Kenny, D. A., \& Malloy, T. E. (1988). Consensus in personality judgments at zero acquaintance. Journal of Personality and Social Psychology, 55, 387-395. doi:10.1037/0022-3514.55.3.387

Ambady, N., \& Rosenthal, R. (1992). Thin slices of expressive behavior as predictors of interpersonal consequences: A meta-analysis. Psychological Bulletin, 111, 256-274. doi:10.1037/0033-2909.111.2.256

Anderson, C., John, O. P., Keltner, D., \& Kring, A. M. (2001). Who attains social status? Effects of personality and physical attractiveness in social groups. Journal of Personality and Social Psychology, 81, 116-132. doi:10.1037/0022-3514.81.1.116

Anderson, C., \& Kilduff, G. J. (2009a). The pursuit of status in social groups. Current Directions in Psychological Science, 18, 295-298. doi:10.1111/j.1467-8721.2009.01655.x

Anderson, C., \& Kilduff, G. J. (2009b). Why do Dominant personalities attain influence in face-to-face groups? The competence-signaling effects of trait Dominance. Journal of Personality and Social Psychology, 96, 491-503. doi:10.1037/a0014201

Anderson, C., \& Shirako, A. (2008). Are individuals' reputations related to their history of behavior? Journal of Personality and Social Psychology, 94, 320-333. doi:10.1037/0022-3514.94.2.320

Anderson, C., Srivastava, S., Beer, J. S., Spataro, S. E., \& Chatman, J. A. (2006). Knowing your place: Self-perceptions of status in face-to-face groups. Journal of Personality and Social Psychology, 91, 1094-1110. doi:10.1037/0022-3514.91.6.1094

Aries, E. J., Gold, C., \& Weigel, R. (1983). Dispositional and situational influences on Dominance behavior in small groups. Journal of Personality and Social Psychology, 44, 779-786. doi:10.1037/0022-3514.44.4 .779 
Awamleh, R., \& Gardner, W. L. (1999). Perceptions of leader charisma and effectiveness: The effects of vision content, delivery, and organizational performance. Leadership Quarterly, 10, 345-373. doi:10.1016/S10489843(99)00022-3

Bakan, D. (1966). The duality of human existence. Skokie, IL: Rand McNally.

Báles, R. F. (1950). Interaction process analysis: A method for the study of small groups. Reading, MA: Addison-Wesley.

Báles, R. F., Strodtbeck, F. L., Mills, T. M., \& Roseborough, M. E. (1951). Channels of communication in small groups. American Sociological Review, 16, 461-468. doi:10.2307/2088276

Barkow, J. H. (1975). Prestige and culture: A biosocial interpretation. Current Anthropology, 16, 553-572. doi:10.1086/201619

Barkow, J. H. (1989). Darwin, sex, and status: Biological approaches to mind and culture. Toronto, Canada: University of Toronto Press.

Barth, E. A., \& Noel, D. L. (1972). Conceptual frameworks for the analysis of race relations: An evaluation. Social Forces, 50, 333-348.

Bass, B. M. (1990). Bass and Stogdill's handbook of leadership: Theory, research, and managerial applications (3rd ed.). New York, NY: Free Press.

Berger, J., Cohen, B. P., \& Zelditch, M. (1972). Status characteristics and social interaction. American Sociological Review, 37, 241-255. doi: $10.2307 / 2093465$

Berger, J., Rosenholtz, S. J., \& Zelditch, M. (1980). Status organizing processes. Annual Review of Sociology, 6, 479-508. doi:10.1146/ annurev.so.06.080180.002403

Bernstein, I. S. (1970). Primate status hierarchies. In L. A. Rosenblum (Ed.), Primate behavior: Developments in field and laboratory research (Vol. 1, pp. 71-109). New York, NY: Academic Press.

Bernstein, I. S. (1976). Dominance, aggression and reproduction in primate societies. Journal of Theoretical Biology, 60, 459-472. doi:10.1016/ 0022-5193(76)90072-2

Bernstein, I. S. (1981). Dominance: The baby and the bathwater. Behavioral and Brain Sciences, 4, 419-457. doi:10.1017/ S0140525X00009614

Betzig, L. L. (1986). Despotism and differential reproduction: A Darwinian view of history. Hawthorne, NY: Aldine.

Betzig, L. L. (1993). Sex, succession, and stratification in the first six civilizations: How powerful men reproduced, passed power on to their sons, and used power to defend their wealth, women, and children. In L. Ellis (Ed.), Social stratification and socioeconomic inequality (Vol. 1, pp. 37-74). Westport, CT: Praeger.

Blader, S. L., \& Chen, Y.-R. (2012). Differentiating the effects of status and power: A justice perspective. Journal of Personality and Social Psychology, 102, 994-1014. doi:10.1037/a0026651

Blau, P. M. (1964). Exchange and power in social life. New York, NY: Wiley.

Bliese, P. (2012). Multilevel: Multilevel Functions. (R package Version 2.4) [Computer software]. Retrieved from http://cran.r-project.org

Bliese, P. D., \& Hanges, P. J. (2004). Being both too liberal and too conservative: The perils of treating grouped data as though they were independent. Organizational Research Methods, 7, 400-417. doi: 10.1177/1094428104268542

Boehm, C. (1993). Egalitarian society and reverse Dominance hierarchy. Current Anthropology, 34, 227-254. doi:10.1086/204166

Boldry, J. G., \& Gaertner, L. (2006). Separating status from power as an antecedent of intergroup perception. Group Processes \& Intergroup Relations, 9, 377-400. doi:10.1177/1368430206064640

Bottger, P. C. (1984). Expertise and air time as basis of actual and perceived influence in problem solving groups. Journal of Applied Psychology, 69, 214-221. doi:10.1037/0021-9010.69.2.214

Boyd, R., \& Richerson, P. J. (1985). Culture and the evolutionary process. Chicago, IL: University of Chicago Press.
Brown, D. (1991). Human universals. Philadelphia. PA: Temple University Press.

Brunell, A. B., Gentry, W. A., Campbell, W. K., Hoffman, B. J., Kuhnert, K. W., \& DeMarree, K. G. (2008). Leader emergence: The case of the narcissistic leader. Personality and Social Psychology Bulletin, 34, 1663-1676. doi:10.1177/0146167208324101

Bryk, A. S., \& Raudenbush, S. W. (1992). Hierarchical linear models: Applications and data analysis methods. Thousand Oaks, CA: Sage.

Buss, D. M. (2008). Evolutionary psychology: The new science of the mind (3rd ed.). Boston, MA: Allyn \& Bacon.

Buss, D. M., \& Craik, K. H. (1980). The frequency concept of disposition Dominance and prototypical Dominant acts. Journal of Personality, 48, 379-392. doi:10.1111/j.1467-6494.1980.tb00840.x

Buss, D. M., \& Duntley, J. D. (2006). The evolution of aggression. In M. Schaller, J. A. Simpson, \& D. T. Kenrick (Eds.), Evolution and social psychology (pp. 263-285). New York: Psychology Press.

Buss, D. M., Gomes, M., Higgins, D. S., \& Lauterbach, K. (1987). Tactics of manipulation. Journal of Personality and Social Psychology, 52, 1219-1229. doi:10.1037/0022-3514.52.6.1219

Buttermore, N. (2006, June). Distinguishing Dominance and Prestige: Validation of a self-report scale. Poster presented at the annual meeting of the Human Behavior and Evolution Society, Philadelphia, PA.

Carli, L. L., \& Eagly, A. H. (1999). Gender effects on social influence and emergent leadership. In G. N. Powell (Ed.), Handbook of gender and work (pp. 203-222). Thousand Oaks, CA: Sage. doi:10.4135/ 9781452231365.n11

Carson, R. C. (1969). Interaction concepts of personality. Chicago, IL: Aldine.

Cartwright, D. (1959). A field theoretical conception of power. In D Cartwright (Ed.), Studies in social power (pp. 183-220). Ann Arbor, MI: Institute for Social Research.

Cashdan, E. (1998). Smiles, speech, and body posture: How women and men display sociometric status and power. Journal of Nonverbal Behavior, 22, 209-228. doi:10.1023/A:1022967721884

Casimir, M. J., \& Rao, A. (1995). Prestige, possessions, and progeny. Human Nature, 6, 241-272. doi:10.1007/BF02734141

Chagnon, N. (1983). Yanomamo (3rd ed.). New York, NY: Holt, Rinehart, \& Winston.

Chance, M. R. A. (1967). Attention structure as the basis of primate rank orders. Man, 2, 503-518. doi:10.2307/2799336

Chance, M. R. A., \& Jolly, C. J. (1970). Social groups of monkeys, apes and man. London, England: Cape.

Cheng, J. T., Tracy, J. L., \& Henrich, J. (2010). Pride, personality, and the evolutionary foundations of human social status. Evolution and Human Behavior, 31, 334-347. doi:10.1016/j.evolhumbehav.2010.02.004

Cohen, E. (1994). Designing groupwork: Strategies for the heterogeneous classroom. New York, NY: Teachers College Press.

Coie, J. D., Dodge, K. A., \& Coppotelli, H. (1982). Dimensions and types of social status: A cross-age perspective. Developmental Psychology, 18, 557-570. doi:10.1037/0012-1649.18.4.557

Cowlishaw, G., \& Dunbar, R. I. (1991). Dominance rank and mating success in male primates. Animal Behaviour, 41, 1045-1056. doi: 10.1016/S0003-3472(05)80642-6

de Cremer, D., \& van Dijk, E. (2005). When and why leaders put themselves first: Leader behaviour in resource allocations as a function of feeling entitled. European Journal of Social Psychology, 35, 553-563. doi:10.1002/ejsp.260

de Kwaadsteniet, E. W., \& van Dijk, E. (2010). Social status as a cue for tacit coordination. Journal of Experimental Social Psychology, 46, 515524. doi:10.1016/j.jesp.2010.01.005

Deluga, R. J. (1997). Relationship among American presidential charismatic leadership, narcissism, and rated performance. Leadership Quarterly, 8, 49-65. doi:10.1016/S1048-9843(97)90030-8 
DePaulo, B. M., Kenny, D. A., Hoover, C. W., Webb, W., \& Oliver, P. V. (1987). Accuracy of person perception: Do people know what kinds of impressions they convey? Journal of Personality and Social Psychology, 52, 303-315. doi:10.1037/0022-3514.52.2.303

D́epret, E. F., \& Fiske, S. T. (1993). Social cognition and power: Some cognitive consequences of social structure as a source of control deprivation. In G. Weary, F. Gleicher, \& K. Marsh (Eds.), Control motivation and social cognition (pp. 176-202). New York, NY: Springer-Verlag. doi:10.1007/978-1-4613-8309-3_7

de Waal, F. B. (1986). The integration of Dominance and social bonding in primates. Quarterly Review of Biology, 61, 459-479. doi:10.1086/ 415144

Driskell, J. E., Olmstead, B., \& Salas, E. (1993). Task cues, Dominance cues, and influence in task groups. Journal of Applied Psychology, 78, 51-60. doi:10.1037/0021-9010.78.1.51

Eibl-Eibesfeldt, I. (1961). The fighting behavior of animals, Scientific American, 205, 112-123. doi:10.1038/scientificamerican1261-112

Eibl-Eibesfeldt, I. (1970). Ethology: The biology of behavior. New York, NY: Holt, Rinehart and Winston.

Eibl-Eibesfeldt, I. (1989). Human ethology. New York, NY: Aldine de Gruyter.

Ellis, L. (1994). Social stratification and socioeconomic inequality: Vol. 2. Reproductive and interpersonal aspects of Dominance and status. Westport, CT: Praeger.

Ellis, L. (1995). Dominance and reproductive success among nonhuman animals: A cross-species comparison. Ethology and Sociobiology, 16, 257-333. doi:10.1016/0162-3095(95)00050-U

Emerson, R. M. (1962). Power-dependence relations. American Sociological Review, 27, 31-41. doi:10.2307/2089716

Enders, C. K., \& Tofighi, D. (2007). Centering predictor variables in cross-sectional multilevel models: A new look at an old issue. Psychological Methods, 12, 121. doi:10.1037/1082-989X.12.2.121

Exline, R. V., Ellyson, S. L., \& Long, B. (1975). Visual behavior as an aspect of power role relationships. In P. Pliner, L. Krames, \& T. Alloway (Eds.), Nonverbal communication of aggression (pp. 21-52). New York, NY: Plenum Press. doi:10.1007/978-1-4684-2835-3_2

Fast, N. J., \& Chen, S. (2009). When the boss feels inadequate: Power, incompetence, and aggression. Psychological Science, 20, 1406-1413. doi:10.1111/j.1467-9280.2009.02452.x

Firebaugh, G. (1978). A rule for inferring individual-level relationships from aggregate data. American Sociological Review, 43, 557-572. doi: $10.2307 / 2094779$

Fiske, S. T. (1993). Controlling other people: The impact of power on stereotyping. American Psychologist, 48, 621-628. doi:10.1037/0003066X.48.6.621

Fiske, S. T. (2010). Interpersonal stratification: Status, power, and subordination. In S. T. Fiske, G. Lindzey, \& D. T. Gilbert (Eds.), Handbook of social psychology (5th ed., pp. 941-982). Hoboken, NJ: Wiley.

Fiske, S. T., \& Berdahl, J. L. (2007). Social power. In A. W. Kruglanski \& E. T. Higgins (Eds.), Social psychology: A handbook of basic principles (2nd ed., pp. 678-692). New York: Guilford Press.

Flynn, F. J., Reagans, R. E., Amanatullah, E. T., \& Ames, D. R. (2006). Helping one's way to the top: Self-monitors achieve status by helping others and knowing who helps whom. Journal of Personality and Social Psychology, 91, 1123-1137. doi:10.1037/0022-3514.91.6.1123

Foa, U. G., \& Foa, E. B. (1974). Societal structures of the mind. Springfield, IL: Thomas.

Foulsham, T., Cheng, J. T., Tracy, J. L., Henrich, J., \& Kingstone, A. (2010). Gaze allocation in a dynamic situation: Effects of social status and speaking. Cognition, 117, 319-331. doi:10.1016/j.cognition.2010 .09 .003

Fournier, M. A. (2009). Adolescent hierarchy formation and the social competition theory of depression. Journal of Social and Clinical Psychology, 28, 1144-1172. doi:10.1521/jscp.2009.28.9.1144
French, J. R. P., Jr., \& Raven, B. (1959). The bases of social power. In D. Cartwright (Ed.), Studies in social power (pp. 150-167). Ann Arbor, MI: Institute for Social Research.

Fried, M. H. (1967). The evolution of political society: An essay in political anthropology. New York, NY: Random House.

Funder, D. C., \& Colvin, C. R. (1988). Friends and strangers: Acquaintanceship, agreement, and the accuracy of personality judgment. Journal of Personality and Social Psychology, 55, 149-158. doi:10.1037/00223514.55.1.149

Galinsky, A. D., Gruenfeld, D. H., \& Magee, J. C. (2003). From power to action. Journal of Personality and Social Psychology, 85, 453-466. doi:10.1037/0022-3514.85.3.453

Gibb, C. (1968). Leadership. In G. Lindzey \& E. Aronson (Eds.), The handbook of social psychology (2nd ed., pp. 205-283). Reading, MA: Addison-Wesley.

Gilbert, P., Price, J., \& Allan, S. (1995). Social comparison, social attractiveness and evolution: How might they be related? New Ideas in Psychology, 13, 149-165. doi:10.1016/0732-118X(95)00002-X

Gillet, J., Cartwright, E., \& Vugt, M. (2011). Selfish or servant leadership? Evolutionary predictions on leadership personalities in coordination games. Personality and Individual Differences, 51, 231-236. doi: 10.1016/j.paid.2010.06.003

Gintner, G., \& Lindskold, S. (1975). Rate of participation and expertise as factors influencing leader choice. Journal of Personality and Social Psychology, 32, 1085-1089. doi:10.1037/0022-3514.32.6.1085

Goldhamer, H., \& Shils, E. A. (1939). Types of power and status. American Journal of Sociology, 45, 171-182. doi:10.1086/218263

Gough, H. G. (1987). CPI manual (2nd ed.). Palo Alto, CA: Consulting Psychologists Press.

Greenleaf, R. K. (2002). Servant leadership: A journey into the nature of legitimate power and greatness. Mahwah, NJ: Paulist Press.

Griskevicius, V., Tybur, J. M., Gangestad, S. W., Perea, E. F., Shapiro, J. R., \& Kenrick, D. T. (2009). Aggress to impress: Hostility as an evolved context-dependent strategy. Journal of Personality and Social Psychology, 96, 980-994. doi:10.1037/a0013907

Guinote, A., Judd, C. M., \& Brauer, M. (2002). Effects of power on perceived and objective group variability: Evidence that more powerful groups are more variable. Journal of Personality and Social Psychology, 82, 708-721. doi:10.1037/0022-3514.82.5.708

Hardy, C. L., \& Van Vugt, M. (2006). Nice guys finish first: The competitive altruism hypothesis. Personality and Social Psychology Bulletin, 32, 1402-1413. doi:10.1177/0146167206291006

Hawley, P. H. (2002). Social Dominance and prosocial and coercive strategies of resource control in preschoolers. International Journal of Behavioral Development, 26, 167-176. doi:10.1080/01650250042000726

Hawley, P. H. (2003). Strategies of control, aggression, and morality in preschoolers: An evolutionary perspective. Journal of Experimental Child Psychology, 85, 213-235. doi:10.1016/S0022-0965(03)00073-0

Hawley, P. H., Little, T. D., \& Pasupathi, M. (2002). Winning friends and influencing peers: Strategies of peer influence in late childhood. International Journal of Behavioral Development, 26, 466-474. doi: 10.1080/01650250143000427

Henrich, J., \& Gil-White, F. J. (2001). The evolution of Prestige: Freely conferred deference as a mechanism for enhancing the benefits of cultural transmission. Evolution and Human Behavior, 22, 165-196. doi:10.1016/S1090-5138(00)00071-4

Henrich, J., Heine, S. J., \& Norenzayan, A. (2010). The weirdest people in the world? Behavioral and Brain Sciences, 33, 61-83. doi:10.1017/ S0140525X0999152X

Hewstone, M., Rubin, M., \& Willis, H. (2002). Intergroup bias. Annual Review of Psychology, 53, 575-604. doi:10.1146/annurev.psych.53 .100901 .135109 
Hill, J. (1984a). Human altruism and sociocultural fitness. Journal of Social and Biological Structures, 7, 17-35. doi:10.1016/S01401750(84)90062-9

Hill, J. (1984b). Prestige and reproductive success in man. Ethology and Sociobiology, 5, 77-95. doi:10.1016/0162-3095(84)90011-6

Hill, K., \& Hurtado, A. M. (1989). Hunter-gatherers of the New World. American Scientist, 77, 436-443.

Hill, K., \& Hurtado, A. M. (1996). Ache life history: The ecology and demography of a foraging people. Hawthorne, NY: de Gruyter.

Hinde, R. A. (1974). The biological bases of behavior. New York, NY: McGraw-Hill.

Hofmann, D. A., \& Gavin, M. (1998). Centering decisions in hierarchical linear models: Theoretical and methodological implications for research in organizations. Journal of Management, 24, 623-641.

Hold, B. C. L. (1976). Attention structure and rank specific behavior in preschool children. In M. R. A. Chance \& R. R. Larsen (Eds.), The social structure of attention (pp. 177-202). London, NY: Wiley.

Hollander, E. P. (1985). Leadership and power. In G. Lindzey \& E. Aronson (Eds.), The handbook of social psychology (pp. 485-537). New York, NY: Random House.

Hollander, E. P., \& Julian, J. W. (1969). Contemporary trends in the analysis of leadership processes. Psychological Bulletin, 71, 387-397. doi: $10.1037 / \mathrm{h} 0027347$

Hox, J. J. (2010). Multilevel analysis: Techniques and applications (2nd ed.). New York, NY: Routledge Academic.

Iacocca, L. (1984). Iacocca: An autobiography. New York, NY: Bantam Books.

Jackson, D. N. (1999). Personality Research Form manual (3rd ed.). Port Huron, MI: Sigma Assessment Systems.

Johnson, R. T., Burk, J. A., \& Kirkpatrick, L. A. (2007). Dominance and Prestige as differential predictors of aggression and testosterone levels in men. Evolution and Human Behavior, 28, 345-351. doi:10.1016/j .evolhumbehav.2007.04.003

Jolly, A. (1972). The evolution of primate behavior. New York, NY: Macmillan

Jones, J. M. (2011, December 27). Barack Obama, Hillary Clinton again top most admired list. Gallup. Retrieved from http://www.gallup.com/ poll/151790/barack-obama-hillary-clinton-again-top-admired-list.aspx

Jost, J. T., \& Banaji, M. R. (1994). The role of stereotyping in systemjustification and the production of false consciousness. British Journal of Social Psychology, 33, 1-27. doi:10.1111/j.2044-8309.1994.tb01008.x

Keltner, D., Gruenfeld, D. H., \& Anderson, C. (2003). Power, approach, and inhibition. Psychological Review, 110, 265-284. doi:10.1037/0033295X.110.2.265

Kemper, T. D. (1990). Social structure and testosterone: Explorations of the socio-bio-social chain. New Brunswick, NJ: Rutgers University Press.

Kemper, T. D. (2006). Power and status and the power-status theory of emotions. In J. Stets \& J. Turner (Eds.), Handbook of the sociology of emotions (pp. 87-113). New York, NY: Springer. doi:10.1007/978-0387-30715-2_5

Kenny, D. A. (1998). SOREMO [Computer software]. University of Connecticut.

Kenny, D. A., \& Albright, L. (1987). Accuracy in interpersonal perception: A social relations analysis. Psychological Bulletin, 102, 390-402. doi: 10.1037/0033-2909.102.3.390

Kenny, D. A., Albright, L., Malloy, T. E., \& Kashy, D. A. (1994). Consensus in interpersonal perception: Acquaintance and the Big Five. Psychological Bulletin, 116, 245-258. doi:10.1037/0033-2909.116.2 245

Kenny, D. A., Horner, C., Kashy, D. A., \& Chu, L. (1992). Consensus at zero acquaintance: Replication, behavioral cues, and stability. Journal of Personality and Social Psychology, 62, 88-97. doi:10.1037/0022-3514 .62 .1 .88
Kenny, D. A., \& Judd, C. M. (1986). Consequences of violating the independence assumption in analysis of variance. Psychological Bulletin, 99, 422-431. doi:10.1037/0033-2909.99.3.422

Kenny, D. A., Kashy, D. A., \& Cook, W. (2006). Dyadic data analysis. New York, NY: Guilford Press.

Kenny, D. A., \& La Voie, L. (1984). The social relations model. In L. Berkowitz (Ed.), Advances in experimental social psychology (Vol. 18 pp. 142-182). Orlando, FL: Academic Press.

Kipnis, D., Castell, J., Gergen, M., \& Mauch, D. (1976). Metamorphic effects of power. Journal of Applied Psychology, 61, 127-135. doi 10.1037/0021-9010.61.2.127

Krackle, W. H. (1978). Force and persuasion: Leadership in an Amazonian society. Chicago, IL: University of Chicago Press.

Kreft, I., \& de Leeuw, J. (1998). Introducing multilevel modeling. London, England: Sage.

Kreft, I. G. G., de Leeuw, J., \& Aiken, L. S. (1995). The effect of different forms of centering in hierarchical linear models. Multivariate Behavioral Research, 30, 1-21. doi:10.1207/s15327906mbr3001_1

Kyl-Heku, L. M., \& Buss, D. M. (1996). Tactics as units of analysis in personality psychology: An illustration using tactics of hierarchy negotiation. Personality and Individual Differences, 21, 497-517. doi: 10.1016/0191-8869(96)00103-1

La Freniere, P., \& Charlesworth, W. R. (1983). Dominance, attention, and affiliation in a preschool group: A nine-month longitudinal study. Ethology and Sociobiology, 4, 55-67. doi:10.1016/0162-3095(83)90030-4

Laland, K. N., \& Galef, B. G. (2009). The question of animal culture. Cambridge, MA: Harvard University Press.

Leary, T. (1957). Interpersonal diagnosis of personality. New York, NY: Ronald Press.

Lee, M. T., \& Ofshe, R. (1981). The impact of behavioral style and status characteristics on social influence: A test of two competing theories Social Psychology Quarterly, 44, 73-82. doi:10.2307/3033703

Lee, R. B. (1979). The !Kung San: Men, women and work in a foraging society. Cambridge, New York: Cambridge University Press.

Lewin, K. (1951). Field theory in social science: Selected theoretical papers. New York, NY: Harpers.

Lewin, K., Lippitt, R., \& White, R. K. (1939). Patterns of aggressive behavior in experimentally created "social climates." Journal of Social Psychology, 10, 271-299. doi:10.1080/00224545.1939.9713366

Lewis, H. (1974). Leaders and followers: Some anthropological perspectives. Reading, MA: Addison-Wesley.

Lewis, R. J. (2002). Beyond Dominance: The importance of leverage Quarterly Review of Biology, 77, 149-164. doi:10.1086/343899

Littlepage, G. E., Schmidt, G. W., Whisler, E. W., \& Frost, A. G. (1995). An input-process-output analysis of influence and performance in problem-solving groups. Journal of Personality and Social Psychology, 69, 877-889. doi:10.1037/0022-3514.69.5.877

Lord, R. G., de Vader, C. L., \& Alliger, G. M. (1986). A meta-analysis of the relation between personality traits and leadership perceptions: An application of validity generalization procedures. Journal of Applied Psychology, 71, 402-410. doi:10.1037/0021-9010.71.3.402

Lord, R. G., \& Maher, K. J. (1991). Leadership and information processing: Linking perception and performance. Boston, MA: Unwin Hyman.

Lorenz, K. (1964). Ritualized aggression. In J. D. Carthy \& F. J. Ebling (Eds.), The natural history of aggression (pp. 39-50). New York, NY: Academic Press.

Magee, J. C., \& Galinsky, A. D. (2008). Social hierarchy: The selfreinforcing nature of power and status. Academy of Management Annals, 2, 351-398. doi:10.1080/19416520802211628

Malloy, T. E., \& Albright, L. (1990). Interpersonal perception in a social context. Journal of Personality and Social Psychology, 58, 419-428. doi:10.1037/0022-3514.58.3.419 
Malone, S. (2010, April 4). Buffett's Berkshire is best-regarded U.S. company. Reuters. Retrieved from http://www.reuters.com/article/2010/ 04/04/us-corporate-reputation-exclusive-idUSTRE63316320100404

Maner, J. K., DeWall, C. N., \& Gailliot, M. T. (2008). Selective attention to signs of success: Social Dominance and early stage interpersonal perception. Personality and Social Psychology Bulletin, 34, 488-501. doi: $10.1177 / 0146167207311910$

Maner, J. K., \& Mead, N. (2010). The essential tension between leadership and power: When leaders sacrifice group goals for the sake of selfinterest. Journal of Personality and Social Psychology, 99, 482-497. doi: $10.1037 / \mathrm{a} 0018559$

March, J. G. (1956). Influence measurement in experimental and semiexperimental groups. Sociometry, 19, 260-271. doi:10.2307/2785767

Mast, M. S. (2002). Dominance as expressed and inferred through speaking time: A meta-analysis. Human Communication Research, 28, 420-450.

Mather, M., Shafir, E., \& Johnson, M. K. (2000). Misremembrance of options past: Source monitoring and choice. Psychological Science, 11, 132-138. doi:10.1111/1467-9280.00228

Maynard Smith, J. (1974). The theory of games and the evolution of animal conflicts. Journal of Theoretical Biology, 47, 209-221. doi:10.1016/ 0022-5193(74)90110-6

Maynard Smith, J., \& Price, G. R. (1973). The logic of animal conflict. Nature, 246, 15-18. doi:10.1038/246015a0

Mazur, A. (1973). A cross-species comparison of status in small established groups. American Sociological Review, 38, 513-530. doi: $10.2307 / 2094404$

Mazur, A. (1985). A biosocial model of status in face-to-face primate groups. Social Forces, 64, 377-402.

Mazur, A., \& Booth, A. (1998). Testosterone and Dominance in men. Behavioral and Brain Sciences, 21, 353-363. doi:10.1017/ S0140525X98001228

Mesoudi, A. (2008). An experimental simulation of the "copy-successfulindividuals" cultural learning strategy: Adaptive landscapes, producerscrounger dynamics, and informational access costs. Evolution and Human Behavior, 29, 350-363. doi:10.1016/j.evolhumbehav.2008.04 .005

Moore, J. C. (1968). Status and influence in small group interactions. Sociometry, 31, 47-63. doi:10.2307/2786479

Moskowitz, D. S. (1988). Cross-situational generality in the laboratory: Dominance and friendliness. Journal of Personality and Social Psychology, 54, 829-839. doi:10.1037/0022-3514.54.5.829

Moskowitz, D. S., \& Zuroff, D. C. (2005). Assessing interpersonal perceptions using the interpersonal grid. Psychological Assessment, 17, 218-230. doi:10.1037/1040-3590.17.2.218

Mullen, B., Salas, E., \& Driskell, J. E. (1989). Salience, motivation, and artifact as contributions to the relation between participation rate and leadership. Journal of Experimental Social Psychology, 25, 545-559. doi:10.1016/0022-1031(89)90005-X

Murdock. G. P. (1949). Social structure. New York, NY: Free Press.

Murray, H. A. (1938). Explorations in personality. New York, NY: Oxford University Press.

O’Gorman, R., Henrich, J., \& Van Vugt, M. (2009). Constraining freeriding in public goods games: Designated solitary punishers can sustain human cooperation. Proceedings of the Royal Society B: Biological Sciences, 276, 323-329. doi:10.1098/rspb.2008.1082

Plourde, A. M. (2008). The origins of Prestige goods as honest signals of skill and knowledge. Human Nature, 19, 374-388. doi:10.1007/s12110008-9050-4

R Development Core Team. (2006). R: A language and environment for statistical computing. Vienna, Austria: R Foundation for Statistical Computing.

Rabb, G. B., Woolpy, J. H., \& Ginsburg, B. E. (1967). Social relationships in a group of captive wolves. American Zoologist, 7, 305-311.
Raudenbush, S. W., \& Bryk, A. S. (2002). Hierarchical linear models: Applications and data analysis methods (2nd ed.). Thousand Oaks, CA: Sage.

Reyes-García, V., Molina, J. L., Broesch, J., Calvet, L., Huanca, T., Saus, J., Tanner, S., . . McDade, T. W. (2008). Do the aged and knowledgeable men enjoy more Prestige? A test of predictions from the Prestigebias model of cultural transmission. Evolution and Human Behavior, 29 , 275-281. doi:10.1016/j.evolhumbehav.2008.02.002

Reyes-García, V., Molina, J. L., McDade, T. W., Tanner, S. N., Huanca, T., \& Leonard, W. R. (2009). Inequality in social rank and adult nutritional status: Evidence from a small-scale society in the Bolivian Amazon. Social Science \& Medicine, 69, 571-578. doi:10.1016/j.socscimed.2009 .05 .039

Ridgeway, C. L. (1987). Nonverbal behavior, Dominance, and the basis of status in task groups. American Sociological Review, 52, 683-694. doi: $10.2307 / 2095603$

Ridgeway, C., \& Diekema, D. (1989). Dominance and collective hierarchy formation in male and female task groups. American Sociological Review, 54, 79-93. doi:10.2307/2095663

Ridgeway, C. L., \& Walker, H. (1995). Status structures. In K. Cook, G. Fine, \& J. House (Eds.), Sociological perspectives on social psychology (pp. 281-310). New York, NY: Allyn \& Bacon.

Ronay, R., Greenaway, K., Anicich, E. M., \& Galinsky, A. D. (2012). The path to glory is paved with hierarchy: When hierarchical differentiation increases group effectiveness. Psychological Science. Advance online publication. doi:10.1177/0956797611433876

Rosenthal, S. A., \& Pittinsky, T. L. (2006). Narcissistic leadership. Leadership Quarterly, 17, 617-633. doi:10.1016/j.leaqua.2006.10.005

Rowell, T. E. (1974). The concept of social Dominance. Behavioral Biology, 11, 131-154. doi:10.1016/S0091-6773(74)90289-2

Sadalla, E. K., Kenrick, D. T., \& Vershure, B. (1987). Dominance and heterosexual attraction. Journal of Personality and Social Psychology, 52, 730-738. doi:10.1037/0022-3514.52.4.730

Sapolsky, R. M. (2005). The influence of social hierarchy on primate health. Science, 308, 648-652. doi:10.1126/science.1106477

Savin-Williams, R. C. (1976). An ethological study of Dominance formation and maintenance in a group of human adolescents. Child Development, 47, 972-979. doi:10.2307/1128433

Savin-Williams, R. C. (1979). Dominance hierarchies in groups of early adolescents. Child Development, 50, 923-935. doi:10.2307/1129316

Savin-Williams, R. C. (1980). Dominance hierarchies in groups of middle to late adolescent males. Journal of Youth and Adolescence, 9, 75-85. doi:10.1007/BF02088381

Schenkel, R. (1967). Submission: Its features and function in the wolf and dog. American Zoologist, 7, 319-329.

Schjelderup-Ebbe, T. (1935). Social behavior of birds. In C. Murchison (Ed.), A handbook of social psychology (Vol. 2, pp. 947-972). New York, NY: Russell and Russell.

Sherman, S. J. (1983). Expectation-based and automatic behavior: A comment on Lee and Ofshe, and Berger and Zelditch. Social Psychology Quarterly, 46, 66-70. doi:10.2307/3033664

Shrout, P. E., \& Fleiss, J. L. (1979). Intraclass correlations: Uses in assessing rater reliability. Psychological Bulletin, 86, 420-428. doi: 10.1037/0033-2909.86.2.420

Sidanius, J., \& Pratto, F. (1999). Social Dominance: An intergroup theory of social hierarchy and oppression. Cambridge, England: Cambridge University Press. doi:10.1017/CBO9781139175043

Singer, J. D., \& Willett, J. B. (2003). Applied longitudinal data analysis: Modeling change and event occurrence. New York, NY: Oxford University Press.

Snijders, T. A. B., \& Bosker, R. J. (1999). Multilevel analysis: An introduction to basic and advanced multilevel modeling. London, England: Sage. 
Sorrentino, R. M., \& Boutillier, R. G. (1975). The effect of quantity and quality of verbal interaction on ratings of leadership ability. Journal of Experimental Social Psychology, 11, 403-411. doi:10.1016/00221031(75)90044-X

Stogdill, R. M. (1948). Personal factors associated with leadership: A survey of the literature. Journal of Psychology: Interdisciplinary and Applied, 25, 35-71. doi:10.1080/00223980.1948.9917362

Strayer, F. F., Bovenkerk, A., \& Koopman, R. F. (1975). Dominance and affiliation in captive squirrel monkeys (Saimiri sciureus). Journal of Comparative and Physiological Psychology, 89, 308-318. doi:10.1037/ h0076822

Strayer, F. F., \& Strayer, J. (1976). An ethological analysis of social agonism and Dominance relations among preschool children. Child Development, 47, 980-989. doi:10.2307/1128434

Strayer, F. F., \& Trudel, M. (1984). Developmental changes in the nature and function of social Dominance among young children. Ethology and Sociobiology, 5, 279-295. doi:10.1016/0162-3095(84)90007-4

Strodtbeck, F. L. (1951). Husband-wife interaction over revealed differences. American Sociological Review, 16, 468-473. doi:10.2307/ 2088277

Thibaut, J. W., \& Kelley, H. H. (1959). The social psychology of groups. New York, NY: Wiley.

Tiedens, L. Z. (2001). Anger and advancement versus sadness and subjugation: The effect of negative emotion expressions on social status conferral. Journal of Personality and Social Psychology, 80, 86-94. doi:10.1037/0022-3514.80.1.86

Tracy, J. L., Shariff, A. F., \& Cheng, J. T. (2010). A naturalist's view of pride. Emotion Review, 2, 163-177. doi:10.1177/1754073909354627

Trivers, R. (1985). Social evolution. Menlo Park, CA: BenjaminCummings.

Van Kleef, G. A., Homan, A. C., Beersma, B., \& van Knippenberg, D. (2010). On angry leaders and agreeable followers: How leaders' emotions and followers' personalities shape motivation and team performance. Psychological Science, 21, 1827-1834. doi:10.1177/ 0956797610387438

Van Vugt, M. (2006). Evolutionary origins of leadership and followership. Personality and Social Psychology Review, 10, 354-371. doi:10.1207/ s15327957pspr1004_5

Vaughn, B. E., \& Waters, E. (1981). Attention structure, sociometric status, and Dominance: Interrelations, behavioral correlates, and relationships to social competence. Developmental Psychology, 17, 275-288. doi: 10.1037/0012-1649.17.3.275

von Rueden, C., Gurven, M., \& Kaplan, H. (2008). The multiple dimensions of male social status in an Amazonian society. Evolution and Human Behavior, 29, 402-415. doi:10.1016/j.evolhumbehav.2008.05 .001 von Rueden, C., Gurven, M., \& Kaplan, H. (2011). Why do men seek status? Fitness payoffs to Dominance and Prestige. Proceedings of the Royal Society B: Biological Sciences, 278, 2223. doi:10.1098/rspb.2010 .2145

Wasylyshyn, K. M. (2005). The reluctant president. Consulting Psychology Journal: Practice and Research, 57, 57-70. doi:10.1037/1065-9293.57 1.57

Weber, M. (1964). The theory of social and economic organization. New York, NY: Free Press.

Wiggins, J. S. (1979). A psychological taxonomy of trait-descriptive terms: The interpersonal domain. Journal of Personality and Social Psychology, 37, 395-412. doi:10.1037/0022-3514.37.3.395

Wiggins, J. S., \& Trapnell, P. D. (1996). A dyadic-interactional perspective on the five factor model. In J. S. Wiggins (Ed.), The five factor model of personality: Theoretical perspectives (pp. 88-162). New York, NY: Guilford Press.

Wiggins, J. S., Trapnell, P., \& Phillips, N. (1988). Psychometric and geometric characteristics of the Revised Interpersonal Adjective Scales (IAS-R). Multivariate Behavioral Research, 23, 517-530. doi:10.1207/ s15327906mbr2304 8

Willer, R. (2009). Groups reward individual sacrifice: The status solution to the collective action problem. American Sociological Review, 74, 23-43, doi: $10.1177 / 000312240907400102$

Wilson, D. S., Van Vugt, M., \& O'Gorman, R. (2008). Multilevel selection theory and major evolutionary transitions: Implications for psychological science. Current Directions in Psychological Science, 17, 6-9. doi:10.1111/j.1467-8721.2008.00538.x

Wilson, E. O. (1975). Sociobiology: The new synthesis. Cambridge, MA: Harvard University Press.

Winter, D. G. (1988). The power motive in women-and men. Journal of Personality and Social Psychology, 54, 510-519. doi:10.1037/00223514.54.3.510

Wood, B. M. (2006). Prestige or provisioning? A test of foraging goals among the Hadza. Current Anthropology, 47, 383-387. doi:10.1086/ 503068

Wooldridge, J. M. (2003). Cluster-sample methods in applied econometrics. American Economic Review, 93, 133-138. doi:10.1257/ 000282803321946930

Workplace Bullying Institute \& Zogby International. (2010). Results of the 2010 and 2007 U.S. Workplace Bullying Survey. Retrieved from http:// workplacebullying.org/docs/WBI_2010_Natl_Survey.pdf

Zelditch, M. (1968). Social status. In D. Sills (Ed.), International encyclopedia of the social sciences (pp. 250-257). New York, NY: Macmillan.

Received December 6, 2011

Revision received May 31, 2012

Accepted June 4, 2012 